\title{
Simultaneous production of gaseous and liquid biofuels from the synergetic co- valorisation of bio-oil and crude glycerol in supercritical water
}

\author{
J. Remón ${ }^{\mathrm{a}, \mathrm{b}^{*}}$, P. Arcelus-Arrillaga ${ }^{\mathrm{b}}$, L. García ${ }^{\mathrm{a}}$, J. Arauzo ${ }^{\mathrm{a}}$
}

${ }^{a}$ Thermochemical Processes Group (GPT), Aragón Institute for Engineering Research (I3A), Universidad de Zaragoza. Mariano Esquillor s/n, E-50018 Zaragoza, Spain.

${ }^{b}$ Department of Chemical Engineering, Imperial College London, London SW7 2AZ, United Kingdom

*Corresponding author: e-mail: jrn@unizar.es

\section{ABSTRACT}

This work addresses the co-valorisation in supercritical water of bio-oil obtained from the fast pyrolysis of wood and crude glycerol yielded as a by-product during biodiesel production. The experiments were conducted at $380{ }^{\circ} \mathrm{C}$ and 230 bar for 30 minutes with a $\mathrm{Ni}-\mathrm{Co} / \mathrm{Al}-\mathrm{Mg}$ catalyst, analysing the effects on the process of the catalyst loading (0-0.25 g catalyst/g organics) and feed composition (each material alone and all possible binary mixtures). The yields to gas, upgraded bio-oil (liquid) and solid varied as follows: $4-87 \%, 0-46 \%$ and $0-18 \%$, respectively. A synergistic interaction between crude glycerol and bio-oil took place during the upgrading process, which allowed the complete and simultaneous transformation of both materials into gas and liquid bio-fuels with a negligible solid formation. The compositions of the gas and the upgraded liquid can be easy tailored by adjusting the catalyst amount and the composition of the feed. The gas phase was made up of $\mathrm{H}_{2}$ (7-49 vol.\%), $\mathrm{CO}_{2}\left(31-56\right.$ vol.\%), $\mathrm{CO}\left(0-7\right.$ vol.\%) and $\mathrm{CH}_{4}(6-57$ vol.\%) and had a Lower Heating Value (LHV) ranging from 8 to $22 \mathrm{MJ} / \mathrm{m}^{3} \mathrm{STP}$. The upgraded bio-oil consisted of a mixture of carboxylic acids $(0-73 \%)$, furans $(0-7 \%)$, phenols $(0-85 \%)$, ketones $(0-22 \%)$ and cyclic compounds $(0-53 \%)$. The proportions of $\mathrm{C}, \mathrm{H}$ and $\mathrm{O}$ in the liquid shifted between $66-77$ wt.\%, 7-11 wt.\% and 15-25 wt.\%, respectively, while its Higher Heating Value (HHV) ranged from 29 to $34 \mathrm{MJ} / \mathrm{kg}$. An optimum for the simultaneous production of gas and liquid bio-fuels was achieved with a 
solution having equal amounts of each material and employing a catalyst amount of $0.25 \mathrm{~g}$ catalyst/g organics. Under such conditions, $37 \%$ of the bio-oil was transformed into an upgraded liquid having a $\mathrm{HHV}(32 \mathrm{MJ} / \mathrm{kg})$ two times higher than the original material $(16 \mathrm{MJ} / \mathrm{kg}$ ) with a negligible solid formation; the rest of the biooil and all the crude glycerol being converted into a rich $\mathrm{CH}_{4}$ (55 vol.\%) biogas with a high LHV (21 MJ/m³ STP). This represents a step-change in future energy production and can help to establish the basis for a more efficient and sustainable biomass valorisation.

Keywords: biofuels, bio-oil, crude glycerol, supercritical water, co-valorisation

\section{Introduction}

The development of more sustainable strategies and unconventional technologies has become a very important issue to satisfy the energy, chemicals and material consumption requirements of the present-day society and the well-being future generations. Under this new scenario, biomass is considered a feedstock with great potential and the valorisation of biomass wastes and residues is gaining increasing attention in the search to replace fossil fuels [1]. Among the different biomass feedstocks, bio-oil [2] produced from the pyrolysis of agroforestry residues and crude glycerol [3] yielded as a by-product during biodiesel production are regarded as two excellent starting materials for the sustainable production of energy and chemicals.

Bio-oil, a bio-based material with high potential for biofuel production, is a dark brown liquid obtained after subjecting biomass to a fast pyrolysis step [4-6]. It consists of a complex organic mixture [7] with different chemical compositions depending on the 
biomass source and the pyrolysis step [8]. Despite of its good potential to be used for biofuel production, some of its physicochemical properties (high viscosity and $\mathrm{O} / \mathrm{C}$ ratio, large $\mathrm{H}_{2} \mathrm{O}$ content and acidity) hinder its direct use as a liquid biofuel [9] and some upgrading treatments such as hydrocracking, hydrotreating, the use of supercritical water $[4-6,10]$ and/or supercritical ethanol $[11,12]$ are required. Among these, supercritical water (SCW) has recently appeared as an up-and-coming methodology for bio-oil valorisation [13] in order to improve the physicochemical characteristics of this feedstock to produce a liquid product with suitable fuel properties [10]. The works addressing lignocellulosic bio-oil upgrading in supercritical water are rare. They can be classified into two categories: gas or liquid focused. Penninger and Rep [14] studied the reforming of bio-oil for the production of a hydrogen rich gas in supercritical conditions, while Onwudili and Williams [15] addressed supercritical water gasification for the production of methane. As regards the production of liquid bio-fuels, Remón et al. [10] investigated the use of water in sub- and supercritical conditions using a Ni-Co/Al-Mg catalyst for the upgrading of lignocellulosic bio-oil for biofuel production. In addition, several Ni-Co catalysts supported on carbon nanofibres (CNFs) were also tested for bio-oil valorisation [16].

However, one of the major drawbacks for the development and scale-up of this technology is the formation of carbonaceous solid (char and/or coke) which not only leads to operational problems but also deactivates the catalyst. This solid formation is accounted for by non-volatile species thermal decomposition when the pyrolysis liquids are processed at high temperature [13]. A good approach to diminishing the formation of carbonaceous solids is the use of catalysts, as they help inhibit the formation of char and/or favour its gasification, which also helps to the reduce the formation of solid 
residues [17]. Zhang et al. [18] conducted hydrolysis and oxidative hydrolysis to convert the pyrolytic sugars, aldehydes and ketones present in the bio-oil into carboxylic acids prior to bio-oil upgrading via decarboxylation. With the aid of the hydrolysis pre-treatment, the upgraded bio-oil yield increased from 27.55 to $30.74 \%$, while the char yield decreased from 5.67 to $3.81 \%$ in comparison with the results without hydrolysis. Another method is the use of hydrogen donor solvents. These liquids can help to reduce coke formation by improving the stability of bio-oil in the face of temperature effects. In addition, the solvation properties of these solvents also enhance the transportation of bio-oils, avoiding blockages if flow reactors are used. One of the main advantages of using hydrogen donor solvents over pure hydrogen is their greater effectiveness in stabilising the primary bio-oil decomposition products, thus preventing charring and coking [5, 19].

The selection of a solvent can have a profound effect on the product distribution during bio-oil upgrading. A number of compounds could be used as hydrogen donors for biooil upgrading as long as they contain mobile carbon-hydrogen bonds, readily dehydrogenate and enhance the solvation capabilities of the bio-oil [5, 19]. Among these, methanol, ethanol, butanol, formic acid and acetic acid have been used as hydrogen donors in hydrodeoxygenation reactions [5, 6]. However, the use of these solvents may be too expensive to make the process economically feasible at a large scale, and therefore future research should focus on the use of low value chemicals and/or by-products produced in other processes for use as cost-effective hydrogen donors for bio-oil upgrading. For example, Ma et al. [2] addressed the co-valorisation of bio-oil and kitchen waste oil by fluid catalytic cracking (FCC) using a HZSM-5 catalyst and found a synergetic interaction between feedstocks. Under these economic 
circumstances, crude glycerol appears as a very promising hydrogen donor for bio-oil upgrading because of its ample availability as a biodiesel by-product (around $1 \mathrm{~kg}$ of crude glycerol is yielded with the production of $10 \mathrm{~kg}$ of biodiesel [20]). Crude glycerol consists not only of glycerol but also of many other impurities such as methanol, soap, catalyst, salts and non-glycerol organic matter [20], and the valorisation of this feedstock by means of a supercritical water treatment remains a challenge. However, its use without any previous purification step contributes to increasing the profitability and sustainability of the valorisation step and must be attempted.

Glycerol has shown very promising results as a substitute for current supercritical fluids [6]. Specifically, reagent grade and crude glycerol has been used as an organic solvent for biomass delignification and the hydrothermal liquefaction of biomass [6]. However, to the best of the authors' knowledge, crude glycerol has never been used as a hydrogen donor and/or co-feeding material for bio-oil upgrading in SCW. The supercritical water reforming of glycerol with or without catalyst yields low molecular weight liquids and permanent gases. The composition of the gas (a mixture comprising $\mathrm{H}_{2}, \mathrm{CO}_{2}, \mathrm{CO}$ and $\mathrm{CH}_{4}$ ) depends on the operating conditions, the catalyst and the glycerol purity. Therefore, extensive research has been conducted aiming at maximising both the glycerol conversion and $\mathrm{H}_{2}$ production while minimising char and coke production [21]. There are several works examining the effects of the operating conditions and catalyst type during the supercritical water reforming of pure glycerol [21]. However, the works addressing the use of crude glycerol are very scarce. Onwudili and Williams [22] studied the reforming of crude glycerol in sub- and supercritical water in the presence of $\mathrm{NaOH}$. By increasing the amount of this salt, coke formation was suppressed, more $\mathrm{H}_{2}$ was produced and the concentrations of $\mathrm{CO}, \mathrm{CO}_{2}$ and hydrocarbons decreased. Van 
Bennekom et al. [23] investigated the supercritical water reforming of pure glycerol and crude glycerol. The experiments were performed both in a laboratory scale unit $(1 \mathrm{~L} / \mathrm{h})$ and a pilot plant $(10 \mathrm{~L} / \mathrm{h})$ at temperatures between 723 and $923 \mathrm{~K}$ and pressures between 25.5 $\mathrm{MPa}$ and $27 \mathrm{MPa}$. It was found that coke formation was negligible and the conversion of glycerol increased with temperature and residence time. $\mathrm{Yu}-\mathrm{Wu}$ et al. [24] analysed the supercritical water reforming of both crude glycerol and pure glycerol in a batch reactor. They observed that the use of crude glycerol favoured the formation of light hydrocarbons, while pure glycerol promoted $\mathrm{H}_{2}$ production due to the presence of sodium salts in crude glycerol.

Given this scenario, this work firstly addresses the co-valorisation of bio-oil and crude glycerol in supercritical water to achieve a simultaneous production of biofuels, aiming to find optimum conditions to achieve a synergetic valorisation of these two feedstocks; i.e. minimising coke and char formation as well as maximising the yields and enhancing the properties of the gas and the upgraded liquid produced. This is of paramount importance for the scalability and commercialisation of this process. Runs were performed at $380{ }^{\circ} \mathrm{C}$ and 280 bar for 30 min using a Ni-Co/Al-Mg catalyst and were planned according to a full factorial experimental design to analyse the effects of the feedstock (bio-oil, crude glycerol and all the possible binary mixtures), the catalyst loading (0-0.25 g catalyst/g organics) as well as all the possible interactions between these two variables. The product distribution (gas, upgraded liquid and solid) together with the most representative properties of the reaction products obtained in the process have been thoroughly examined. The fact that the co-valorisation of bio-oil and crude glycerol in SCW has never previously been reported, together with the results provided in the in-depth study addressing the synergetic effects between them, demonstrates that 
this work represents a novel investigation in this field and contributes to the development of novel and more sustainable strategies for biomass valorisation. For these new models, not only is it important to take into consideration the most suitable combination of processing units, but also it is vital to smartly combine the feedstocks to gain the most of potential and interesting synergies between materials.

\section{Experimental}

\subsection{Bio-oil and crude glycerol characterisation}

Table 1. Feedstocks characterisation. Results are presented as mean \pm standard deviation.

\begin{tabular}{|c|c|c|c|}
\hline & Bi-oil & & Crude glycerol \\
\hline \multicolumn{4}{|l|}{ Composition } \\
\hline Organics (wt.\%) & 60.95 & & $96.31 \pm 2.20$ \\
\hline Ashes (wt.\%) & $<0.001$ & & $2.06 \pm 0.23$ \\
\hline $\mathrm{H}_{2} \mathrm{O}($ wt. $\%)$ & $39.05 \pm 0.39$ & & $1.63 \pm 0.02$ \\
\hline \multicolumn{4}{|l|}{ Ultimate Analysis (raw basis) } \\
\hline $\mathrm{C}($ wt. $\%)$ & $32.86 \pm 0.40$ & & $40.48 \pm 0.29$ \\
\hline $\mathrm{H}(\mathrm{wt} . \%)$ & $6.73 \pm 0.16$ & & $8.19 \pm 0.06$ \\
\hline $\mathrm{O}(\mathrm{wt} . \%)^{\mathrm{a}}$ & $58.91 \pm 0.48$ & & $51.33 \pm 0.34$ \\
\hline N (wt.\%) & $0.51 \pm 0.03$ & & 0 \\
\hline S (wt.\%) & $0.99 \pm 0.11$ & & 0 \\
\hline \multicolumn{4}{|l|}{ Physical properties } \\
\hline $\mathrm{pH}$ & $2.45 \pm 0.02$ & & $13.1 \pm 0.3$ \\
\hline Density $(\mathrm{g} / \mathrm{mL})$ & $1.16 \pm 0.01$ & & $1.060 \pm 0.001$ \\
\hline Viscosity $(\mathrm{mPa} \cdot \mathrm{s})$ & $10.44 \pm 0.48$ & & $49.93 \pm 1.48$ \\
\hline HHV $(\mathrm{MJ} / \mathrm{kg})$ dry basis & $16.52 \pm 0.48$ & & $21.89 \pm 0.05$ \\
\hline Chemical Composition (Area \%) & & Chemical Composition (wt.\%) & \\
\hline Ketones & $18.22 \pm 0.38$ & Glycerol & $63.17 \pm 2.26$ \\
\hline Carboxylic Acids & $45.52 \pm 2.42$ & $\mathrm{MeOH}$ & $34.37 \pm 2.13$ \\
\hline Furans & $3.71 \pm 0.32$ & Others & $<0.83$ \\
\hline Alcohols & $2.22 \pm 0.35$ & & \\
\hline Aldehydes & $1.41 \pm 0.32$ & & \\
\hline Phenols & $21.35 \pm 1.19$ & & \\
\hline Benzenes & $3.86 \pm 1.93$ & & \\
\hline Sugars & $1.99 \pm 1.14$ & & \\
\hline Nitrogen compounds & $1.72 \pm 0.51$ & & \\
\hline
\end{tabular}


The bio-oil, provided by the Biomass Technology Group (BTG) in the Netherlands, was produced during the pyrolysis of pine sawdust using a rotating cone reactor. Table 1 lists the physicochemical properties of the original liquid. Further information about the methodology and apparatus used for the characterisation of the bio-oil can be found in a previous communication [10]. The crude glycerol used for this work is the by-product of the transesterification of sunflower oil with methanol, employing $\mathrm{KOH}$ as a catalyst. Its properties are summarised in Table 1. The crude glycerol is made up of glycerol, methanol, $\mathrm{KOH}$ and fatty acid methyl esters (linoleic $\left(\mathrm{C}_{19} \mathrm{H}_{34} \mathrm{O}_{2}\right)$, palmitic $\left(\mathrm{C}_{17} \mathrm{H}_{34} \mathrm{O}_{2}\right)$, oleic $\left(\mathrm{C}_{19} \mathrm{H}_{36} \mathrm{O}_{2}\right)$, and stearic $\left(\mathrm{C}_{19} \mathrm{H}_{38} \mathrm{O}_{2}\right)$ acids $)$. The properties of this crude glycerol are consistent with those described in other works reported in the literature [25-27].

\subsection{Experimental system}

The influence of the feedstock, calculated as the relative amount of crude glycerol $(0-$ 100 wt.\%) with respect to the total amount of organics in the solution in dry basis (crude glycerol + bio-oil), and the catalyst loading (0-0.25 g catalyst/g organics) was analysed experimentally at $380^{\circ} \mathrm{C}$ and 230 bar using an organic to water ratio of $1 / 10$ and a reaction time of 30 minutes. The water used in each experiment was calculated having regard to the organic/water ratio and the amount of water present in both feedstocks. The catalyst plays an important role in the process. In particular, it must have high deactivation resistance and sufficient strength [28, 29]. A good approach to this challenge is using Ni-based catalysts. A Ni-Co/Al-Mg catalyst was selected for this work. This catalyst was proved to be suitable for the catalytic steam reforming of bio-oil aqueous fractions [30, 31], glycerol [32] and the sub- and supercritical water reforming of bio-oil [10]. The catalyst includes $\mathrm{Ni}$ as the active phase and was modified with $\mathrm{Mg}$ 
and $\mathrm{Co} . \mathrm{Mg}$ was added as a support modifier, enhancing the water adsorption in order to gasify the coke or its precursors, as well as to provide more attrition resistance. Co was added as an active phase modifier to enhance the reforming and WGS reactions and prevent catalyst deactivation by coking, as a Ni-Co interaction can be formed in the catalyst which reduces the crystallite size [31]. The characterisation of this catalyst revealed that it has $28 \% \mathrm{Ni}$ expressed as $\mathrm{Ni} /(\mathrm{Ni}+\mathrm{Co}+\mathrm{Al}+\mathrm{Mg}$ ) (atomic percentage), an atomic $\mathrm{Mg} / \mathrm{Al}$ ratio of 0.26 and an atomic $\mathrm{Co} / \mathrm{Ni}$ ratio of 0.10 , with a $\mathrm{BET}$ surface area of about $132 \mathrm{~m}^{2} / \mathrm{g}[31]$.

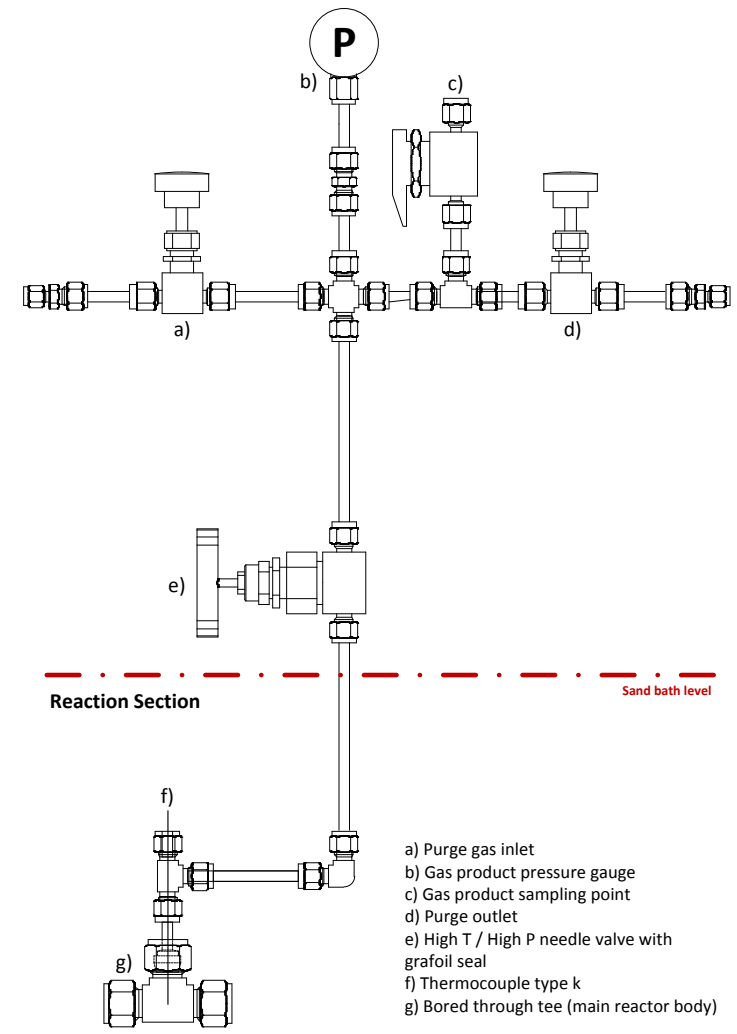

Figure 1. Schematic of the micro-bomb batch reactor.

The experiments were conducted in a stainless steel micro-bomb batch reactor (Figure 1). It consists of a $1 / 2$ inch Swagelok bored-through tee with the two ends plugged and has a total inner volume of $12 \mathrm{~mL}$. The tee was connected by means of a $1 / 4$ inch tube with a wall thickness of 0.069 inches to a high pressure-high temperature needle valve. 
The design and operation have previously been discussed elsewhere [10, 33]. The gas, liquid (upgraded bio-oil) and solid products were recovered, measured and characterised following the experimental procedure described in a previous communication [10].

Table 2. Response variables.

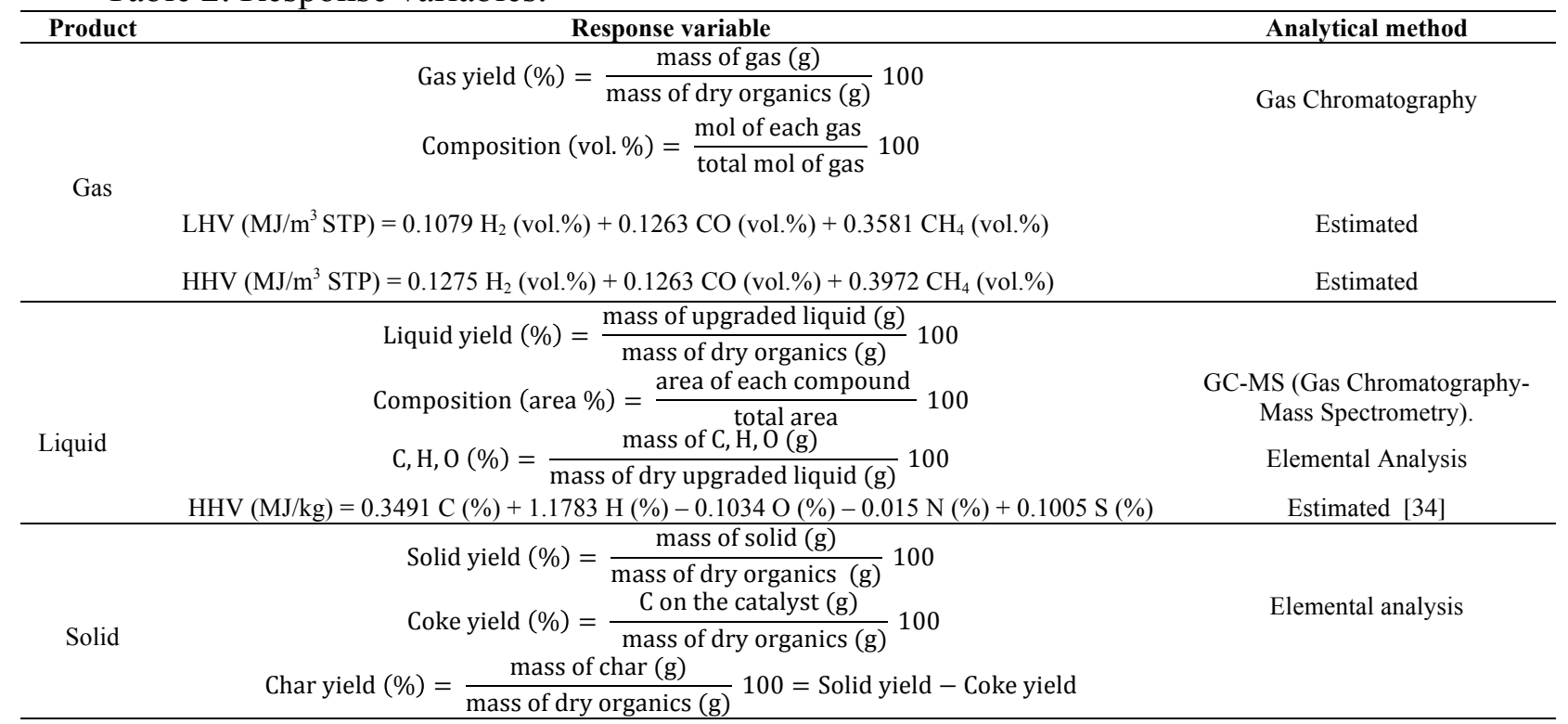

\subsection{Experimental plan and statistical analysis}

The effect of the glycerol/organics and catalyst/organics ratios has been evaluated for the following response variables: yields (\%) to gas, liquid (upgraded bio-oil) and the chemical compositions and calorific values of the gas and the liquid produced (Table 2). The higher heating and lower heating values (HHV and LHV) were used to describe the energy content of the upgraded liquid and the gas, respectively. The higher heating value (HHV) is determined by bringing all the products of combustion back to the original pre-combustion temperature and condensing any vapour produced. LHV calculations assume that the water is in the vapour state at the end of combustion, as opposed to the HHV, which assumes that all of the water in a combustion process is in the liquid state after a combustion process. The lower heating value (LHV) is determined by subtracting the enthalpy of vaporisation of the water from the higher 
heating value; i.e. treating any $\mathrm{H}_{2} \mathrm{O}$ formed as a vapour. The energy required to vaporise the water therefore is not released as heat. The empirical calculation developed by Channiwala et al. [34] was used to calculate the HHV of the upgraded bio-oil. This correlation was developed taking into account 225 biomass samples. In addition, nonsignificant differences were found between the HHV of the original bio-oil calculated experimentally using a calorimetric bomb and the value obtained using this correlation [10]. The LHV is commonly used to describe the energy content of gaseous biofuels; while the HHV is widely used for liquid biofuels. However, for comparative purposes, the HHV $\left(\mathrm{MJ} / \mathrm{m}^{3} \mathrm{STP}\right)$ of the gas phase was also determined. From this latter value and considering the composition of the gas, the HHV in mass basis $(\mathrm{MJ} / \mathrm{kg})$ was calculated.

A 2-level 3-factor Box-Wilson Central Composite Face Centred (CCF, $\alpha$ : \pm 1 ) design, corresponding to a $2^{\mathrm{k}}$ factorial design, was used to plan the experiments. In this design $\mathrm{k}$ indicates the number of factors studied (in this case 2 operating variables) and $2^{\mathrm{k}}$ represents the number of runs (in this case 4) for the simple factorial design. In addition, 4 axial experiments were performed to study non-linear effects and interactions, while 3 replicates at the centre point (centre of the variation interval of each factor) were carried out in order to evaluate the experimental error. This experimental design is suitable not only for studying the influence of each variable (linear and quadratic effects) but also for understanding possible interactions between variables. The results were analysed with an ANOVA with 95\% confidence to select the operating variables and interactions that significantly influence the response variables under consideration. In addition, the cause-effect Pareto principle was used to calculate the relative importance of the operating conditions in the response variables. The lower and upper limits of the factors (crude glycerol/total organics and catalyst/total organics mass ratios) were normalised 
from -1 to 1 (codec factors) in the analyses so that all factors vary within the same interval and their relative influence can be calculated and compared. In the ANOVA analyses, the height of the LSD bars was determined by the design, model, confidence level and unexplained variation with $95 \%$ confidence. This allows a rigorous analysis of the experimental data to be conducted. In particular, to ensure a statistically significant difference between the data, the LSD bars must not overlap.

Table 3. Experimental conditions: glycerol/organics and catalyst/organics ratios and experimental results

\begin{tabular}{|c|c|c|c|c|c|c|c|c|c|}
\hline Run & 1 & 2 & 3 & 4 & $5-7$ & 8 & 9 & 10 & 11 \\
\hline Glycerol/organics (g/g) & 0 & 1 & 0 & 1 & 0.5 & 0 & 1 & 0.5 & 0.5 \\
\hline \multicolumn{10}{|c|}{ Global Product distribution } \\
\hline Liquid yield (\%) & 45.11 & 2.28 & 31.74 & 1.8 & $18.93 \pm 0.74$ & 46.22 & 0.62 & 24.84 & 18.18 \\
\hline Solid yield (\%) & 18.21 & 0 & 8.12 & 0.24 & $1.43 \pm 0.15$ & 7.13 & 1.81 & 1.88 & 1.24 \\
\hline Char yield (\%) & 18.21 & 0 & 4.77 & 0.24 & $1.43 \pm 0.63$ & 5.37 & 1.80 & 1.88 & 1.24 \\
\hline \multicolumn{10}{|l|}{ Gas properties } \\
\hline $\mathrm{H}_{2}(\mathrm{vol} . \%)$ & 23.21 & 48.45 & 18.75 & 12.53 & $12.82 \pm 0.62$ & 26.28 & 12.01 & 45.7 & 7.72 \\
\hline $\mathrm{CO}_{2}(\mathrm{vol} . \%)$ & 55.97 & 38.1 & 52.39 & 31.02 & $37.77 \pm 0.54$ & 52.32 & 31.35 & 44.93 & 39.61 \\
\hline CO (vol.\%) & 1.55 & 6.88 & 1.37 & 0.1 & $0.51 \pm 0.27$ & 2.51 & 0.07 & 1.65 & 0.14 \\
\hline $\mathrm{CH}_{4}(\mathrm{vol} . \%)$ & 19.28 & 6.57 & 27.49 & 56.35 & $48.99 \pm 0.84$ & 18.9 & 56.56 & 7.72 & 52.53 \\
\hline $\mathrm{LHV}\left(\mathrm{MJ} / \mathrm{m}^{3} \mathrm{STP}\right)$ & 9.6 & 8.45 & 12.04 & 21.54 & $18.99 \pm 0.27$ & 9.92 & 21.58 & 7.9 & 19.66 \\
\hline $\mathrm{C}(\mathrm{wt} . \%)$ & 67.36 & 66.99 & 76.36 & 65.91 & $73.82 \pm 1.53$ & 70.02 & 68.46 & 75.09 & 72.44 \\
\hline H (wt.\%) & 7.00 & 9.19 & 7.24 & 10.93 & $7.28 \pm 0.18$ & 7.33 & 10.24 & 7.35 & 7.35 \\
\hline $\mathrm{O}(\mathrm{wt} . \%)$ & 25.16 & 23.54 & 15.59 & 20.91 & $18.16 \pm 0.99$ & 20.99 & 19.63 & 17.23 & 18.81 \\
\hline $\mathrm{H} / \mathrm{C}$ & 0.104 & 0.137 & 0.095 & 0.166 & $0.099 \pm 0.002$ & 0.105 & 0.150 & 0.098 & 0.101 \\
\hline $\mathrm{O} / \mathrm{C}$ & 0.374 & 0.351 & 0.204 & 0.317 & $0.246 \pm 0.002$ & 0.300 & 0.287 & 0.229 & 0.260 \\
\hline HHV $(\mathrm{MJ} / \mathrm{kg})$ & 29.19 & 31.77 & 33.59 & 33.83 & $32.63 \pm 0.47$ & 30.91 & 34.01 & 33.09 & 31.98 \\
\hline \multicolumn{10}{|l|}{ Liquid composition } \\
\hline Phenols (Area \%) & 51.92 & 0 & 31.48 & 0 & $52.76 \pm 0.59$ & 41.89 & 0 & 10.03 & 85.33 \\
\hline C. Acids (Area \%) & 17.22 & 72.75 & 0 & 0 & $17.44 \pm 2.77$ & 15.56 & 0 & 22.27 & 0 \\
\hline Cyclics (Area \%) & 0 & 16.08 & 52.45 & 0 & $22.26 \pm 3.70$ & 20.52 & 0 & 36.66 & 9.51 \\
\hline Furans (Area \%) & 6.66 & 0 & 4.77 & 0 & $1.62 \pm 0.91$ & 4.94 & 0 & 0 & 2.34 \\
\hline
\end{tabular}

\section{Results and discussion}

Table 3 lists the different glycerol/organics and catalyst/organics ratios used for the experiments and the experimental results obtained. In these two variables, glycerol refers to all the organics present in crude glycerol, while the term organics denotes all the organics present in both crude glycerol and bio-oil, in both cases in dry basis. The results include the yields to gas, upgraded liquid and solid together with the most 
important properties of the gas and liquid phases such as compositions and calorific values.

\subsection{Gas, liquid and solid yields}

The yields to gas, upgraded liquid (upgraded bio-oil) and solid vary as follows: 4-87\%, $10-46 \%$ and $0-18 \%$, respectively. The wide interval of variation for these variables indicates that the process can be tailored for the production of either gas or liquid products. The gas, liquid and solid yield do not add up to $100 \%$ for all the experiments due to the formation of water-soluble low molecular weight compounds (largely from glycerol) that were not recovered in the liquid product during the liquid-liquid extraction, and therefore remained in the aqueous phase after the experiments. This is notably marked for runs 2 and 10, for which a rich crude glycerol (>50 wt.\%) solution and a low catalyst loading were used. The relative influence of the feedstock composition (crude glycerol/organics ratio) and catalyst loading on the product distribution according to the statistical analysis of the results are shown in Table 4. The statistical analysis of the results reveals that both the feedstock composition (glycerol/organics ratio) and catalyst loading (catalyst/organics ratio) have a significant influence on the process. In addition, significant interactions between both variables occur.

As regards the relative influence of both variables, the cause-effect Pareto analysis indicates that the catalyst loading (both linear and quadratic effects) is the variable exerting the greatest influence on the yield to gas. Moreover, the relative coefficient for this variable in the model shows that increasing the catalyst amount (positive term) leads to an increase in the gas yield. The liquid yield is strongly affected by the 
glycerol/organics ratio; an increase in the proportion of glycerol (negative term) in the mixture leads to a decrease in the amount of the upgraded liquid produced. The solid yield is strongly dependent on the proportion of glycerol in the mixture and the catalyst loading. An increase in both variables leads to a decrease in the proportion of solid. Very interestingly, the quadratic terms for glycerol in the gas and solid yields have a high relative importance. This provides evidence that the increase and decrease observed in gas and solid yield, respectively, are not a consequence of the dilution of the feed, thus suggesting a synergetic interaction between crude glycerol and bio-oil during their co-valorisation under the operating conditions tested in this work. Figure 2 displays the effect of the feedstock and catalyst loading as well as the most important interactions between the variables detected with the ANOVA analysis on the global product distribution.

Table 4. Effects of the glycerol/organics and catalyst/organics ratios on the global product distribution: gas, upgraded liquid and solid yields.

\begin{tabular}{lllllllllll}
\hline Response & $\mathbf{R}^{2}$ & $\mathbf{I n d}$ & $\mathbf{G}$ & $\mathbf{C}$ & $\mathbf{G C}$ & $\mathbf{G}^{2}$ & $\mathbf{C}^{2}$ & $\mathbf{G}^{2} \mathbf{C}$ & $\mathbf{G C}^{2}$ & $\mathbf{G}^{2} \mathbf{C}^{2}$ \\
\hline Gas yield (\%) & 0.98 & 73.33 & 12.74 & 28.45 & 14.70 & -11.25 & -16.41 & n.s. & -14.14 & n.s. \\
& & & $(5)$ & $(40)$ & $(17)$ & $(15)$ & $(15)$ & & $(9)$ & \\
Liquid yield (\%) & \multirow{2}{*}{1} & \multirow{2}{*}{18.93} & -22.80 & -3.42 & 3.23 & 4.49 & 2.58 & n.s. & 4.60 & -5.78 \\
& & & $(64)$ & $(11)$ & $(8)$ & $(3)$ & $(1)$ & & $(7)$ & $(6)$ \\
Solid yield (\%) & \multirow{2}{*}{1} & \multirow{2}{*}{1.48} & -2.67 & -0.32 & 2.58 & 2.98 & n.s. & -2.14 & -3.86 & 2.18 \\
& & & $(33)$ & $(11)$ & $(13)$ & $(19)$ & & $(6)$ & $(11)$ & $(6)$ \\
\hline
\end{tabular}

Response $=$ Ind. $+\mathrm{G}$ term $\cdot \mathrm{G}+\mathrm{C}$ term $\cdot \mathrm{C}+\mathrm{GC}$ term $\cdot \mathrm{G} \cdot \mathrm{C}+\mathrm{G}^{2}$ term $\cdot \mathrm{G}^{2}+\mathrm{C}^{2}$ term $\cdot \mathrm{C}^{2}+\mathrm{G}^{2} \mathrm{C}$ term $* \mathrm{C}+\mathrm{GC} \mathrm{term}^{2} \cdot \mathrm{G} \cdot \mathrm{C}^{2}+\mathrm{G}{ }^{2} \mathrm{C}^{2}$ $\operatorname{term} \cdot \mathrm{G}^{2} \cdot \mathrm{C}^{2}$

$\mathrm{G}=$ glycerol/glycerol+bio-oil $\quad \mathrm{C}=$ catalyst/glycerol+bio-oil. Numbers in brackets indicate the percentage Pareto influence of each factor on the response variable. Pareto values represent the percentage of the orthogonal estimated total value. n.s. $=$ Non significant with $95 \%$ confidence.

Figure 2 shows that the influence of the feedstock composition on the global yields depends on the amount of catalyst and vice versa due to the significant interactions detected between both variables. On the one hand, in the absence of a catalyst, higher yields to gas, upgraded liquid (bio-oil) and solid are obtained with bio-oil than with crude glycerol; the progressive addition of the latter into the system results in a decrease 
in all these yields. The decrease observed in gas formation is thought to be the consequence of the lower reactivity of crude glycerol than that of bio-oil in the absence of a catalyst. Bio-oil consists of a complicated mixture of chemicals whose reactivity could be higher than that of crude glycerol $[10,16]$. This reactivity observed in the experiments conducted with bio-oil is in good agreement with the results reported our previous work in which bio-oil upgrading was conducted in sub- and supercritical water $[10,16]$. On the other hand, in the presence of a catalyst, the decrease observed in the liquid and solid yields also takes place. However, the gas yield increases with the progressive addition of crude glycerol in the mixture, allowing a higher gas yield to be produced with crude glycerol than with bio-oil. This is of paramount importance for the co-valorisation of both feedstocks as this development allows the co-production of gaseous (mainly from glycerol) and liquid (principally from bio-oil) biofuels in one single reactor.
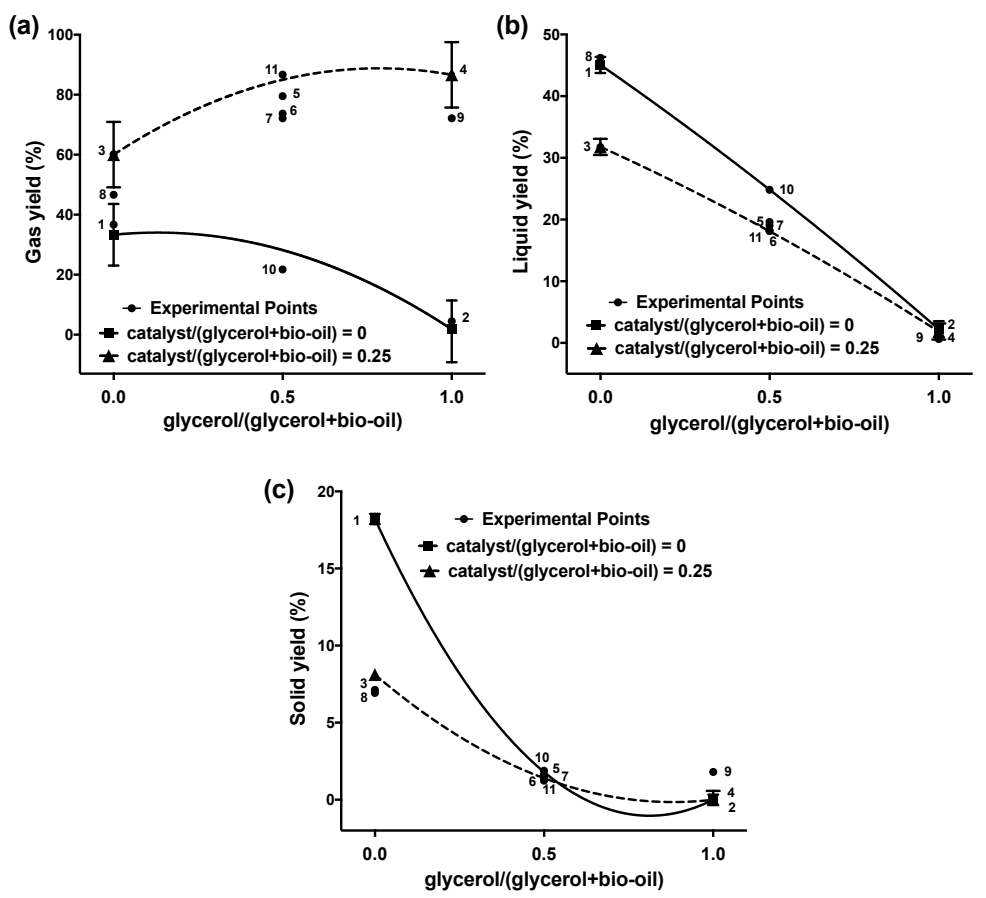

Figure 2. Influence of the feedstock composition and catalyst loading on the global product distribution. Bars are LSD intervals with 95\% confidence. 
Very interestingly, while the decrease observed in the bio-oil yield with the addition of crude glycerol approaches a linear trend, the evolution of the solid yield is not linear. This is in good agreement with the cause-effect Pareto test and suggests that the decrease in the liquid yield with the addition of glycerol is due to a dilution effect and that glycerol is preferentially transformed into gases and water-soluble liquids [21]. In the absence of a catalyst, crude glycerol reacts to produce small amounts of gas and liquid products remaining in the water after reaction and liquid-liquid separation performed with chloroform. Under such conditions it is known that crude-glycerol undergoes hydration, dehydration and hydrolysis reactions in SCW resulting in water soluble chemicals with low molecular weight, such as carboxylic acids, alcohols and ketones [21]. Increasing the amount of catalyst favours the production of gas. This development leads to a linear decrease in the liquid (upgraded bio-oil) yield, which suggests that a simple dilution effect is taking place.

It is observed that the evolution of the solid yield does not follow a linear trend. This variable shows a sharp decrease from $18 \%$ (without catalyst) or $8 \%$ (with catalyst) to a negligible amount of solid (regardless of the catalyst amount) when the proportion of crude glycerol in the mixture increases from 0 to $0.5 \mathrm{~g}$ crude glycerol $/ \mathrm{g}$ organics. This suggests that glycerol plays an important role in preventing solid production during biooil upgrading in SCW. The presence of mobile carbon-hydrogen bonds in crude glycerol which readily dehydrogenate and enhance the solvation capabilities of the biooil $[5,19]$ can help decrease and/or inhibit solid formation. It has been reported that char formation takes place at the early stage of the process during the heating up of the feedstock [10]. Therefore, the inclusion in the process of hydrogen donor solvents, such as glycerol, helps to stabilise char precursors formed at early reaction stages, which 
prevents charring and coking [5]. In addition, solid formation could also have been decreased via the Boudouard $\left(\mathrm{C}+\mathrm{CO}_{2} \Leftrightarrow 2 \mathrm{CO}\right)$ and methanation $\left(\mathrm{C}+2 \mathrm{H}_{2} \Leftrightarrow \mathrm{CH}_{4}\right)$ reactions occurring with the gases produced during the decomposition of crudeglycerol.

As a result, for a feed solution containing equal amounts of bio-oil and crude glycerol ( $0.5 \mathrm{~g}$ crude glycerol/g organics), solid formation is negligible regardless of the catalyst loading. In the absence of a catalyst, the liquid yield is around $28 \% \mathrm{~g}$ upgraded bio-oil $/ \mathrm{g}$ organics, which equals 56\% g upgraded bio-oil/g original bio-oil (assuming a negligible contribution of crude glycerol to this yield). This value decreases down to around $40 \% \mathrm{~g}$ upgraded bio-oil/g original bio-oil when the highest amount of catalyst is used due to the greater gas production in the presence of a catalyst. This development is thought to be the consequence of the greater production of gas with a catalyst than in the absence of a catalyst. These two values are higher than those produced during the valorisation of bio-oil alone ( $45 \%$ and $32 \%$ without and with catalyst, respectively) due to the substantial decrease in solid production, thus highlighting the positive effect that crude glycerol exerts on the valorisation of lignocellulosic bio-oil in SCW.

Increasing the catalyst loading from 0 to $0.25 \mathrm{~g}$ catalyst/g organics produces an increase in the gas yield together with a decrease in the yields to liquid and solid. This is in good agreement with previous works in which SCW was used for improving the physicochemical properties of bio-oil $[10,15]$. The presence of a catalyst in the process improves gas formation, increasing the reaction rates of the reforming and water gas shift reactions [17, 35-39]. Furthermore, the catalyst might help inhibit char formation 
and/or might favour char gasification, which also contributes to a decrease in the formation of char [17], and therefore the effect of the concentration of crude glycerol on the solid yield is less pronounced. The catalyst thus plays two different roles depending on the mixture composition. On the one hand, for bio-oil rich mixtures, an increase in the catalyst loading significantly decreases the solid and liquid yields, the impact on the latter yield being less important. On the other hand, the gas yield substantially increases when a rich crude-glycerol mixture is used and in this case the effect of the catalyst on the liquid and solid yields is less important. For rich crude glycerol solutions, solid formation is negligible and crude glycerol is transformed into gases or water-soluble organics; therefore, the catalyst effect on the liquid and solid yield is very weak.

\subsection{Gas phase properties}

The gas phase is made up of a mixture of $\mathrm{H}_{2}$ (7-49 vol.\%), $\mathrm{CO}_{2}(31-56$ vol.\%), $\mathrm{CO}(0-7$ vol.\%) and $\mathrm{CH}_{4}(6-57$ vol.\%) and has a Lower Heating Value (LHV) ranging from 8 to $22 \mathrm{MJ} / \mathrm{m}^{3} \mathrm{STP}$. Table 5 lists the influence of the feed composition and catalyst loading on the composition and LHV of the gas phase according to the ANOVA analysis and the cause effect Pareto principle. The catalyst loading is the operating variable exerting the greatest influence on the relative amounts of $\mathrm{H}_{2}$ and $\mathrm{CH}_{4}$ and the LHV of the gas phase. The proportions of these two gases are also significantly affected by the composition of the feed (crude glycerol/organics ratio); however, the influence of this variable is less important. In addition, the coefficients in the model for these two gases shows that increasing the amount of catalyst leads to a decrease in the amount of $\mathrm{H}_{2}$ along with an increase in the relative proportion of $\mathrm{CH}_{4}$ in the gas, thus suggesting that the catalyst is very active for methanation reactions. These latter reactions are thermodynamically favoured at the experimental temperature and pressure used in this 
work. This is in good agreement with our previous publication in which this catalyst was used for the valorisation of bio-oil in SCW and with the work carried out by Van Bennekom et al. [23] who found that Ni-based catalysts are very active towards methanation reactions during glycerol valorisation in SCW. This indicates that methanation and Fischer-Tropsch reactions are favoured at near critical and SCW conditions, resulting in high $\mathrm{CH}_{4}$ production $[14,36,40]$.

Table 5. Effects of the glycerol/organics and catalyst/organics ratios on the gas phase properties.

\begin{tabular}{|c|c|c|c|c|c|c|c|c|c|c|}
\hline Response & $\mathbf{R}^{2}$ & Ind & $\mathbf{G}$ & $\mathbf{C}$ & GC & $\mathbf{G}^{2}$ & $\mathbf{C}^{2}$ & $\mathbf{G}^{2} \mathbf{C}$ & GC $^{2}$ & $\mathbf{G}^{2} \mathbf{C}^{2}$ \\
\hline $\mathrm{H}_{2}($ vol.\%) & 1 & 12.82 & $\begin{array}{l}-7.14 \\
(2)\end{array}$ & $\begin{array}{l}-18.99 \\
(31)\end{array}$ & $\begin{array}{l}-7.87 \\
(15)\end{array}$ & $\begin{array}{l}6.33 \\
(8)\end{array}$ & $\begin{array}{l}13.89 \\
(15)\end{array}$ & $\begin{array}{l}8.89 \\
(10)\end{array}$ & $\begin{array}{l}11.89 \\
(13)\end{array}$ & $\begin{array}{l}-7.30 \\
(6)\end{array}$ \\
\hline $\mathrm{CO}_{2}(\mathrm{vol} . \%)$ & 1 & 37.77 & $\begin{array}{l}-10.03 \\
(53)\end{array}$ & $\begin{array}{l}-2.66 \\
(14)\end{array}$ & $\begin{array}{l}-0.88 \\
(4)\end{array}$ & $\begin{array}{l}4.06 \\
(14)\end{array}$ & $\begin{array}{l}4.50 \\
(12)\end{array}$ & n.s. & n.s. & $\begin{array}{l}-1.96 \\
(3)\end{array}$ \\
\hline $\mathrm{CO}(\mathrm{vol} . \%)$ & 0.95 & 0.84 & $\begin{array}{l}-1.22 \\
(5)\end{array}$ & & $\begin{array}{l}-1.65 \\
(26)\end{array}$ & n.s. & n.s. & $\begin{array}{l}-1.74 \\
(28)\end{array}$ & $\begin{array}{l}2.23 \\
(20)\end{array}$ & $\begin{array}{l}1.63 \\
(21)\end{array}$ \\
\hline $\mathrm{CH}_{4}(\mathrm{vol} . \%)$ & 1 & 48.99 & $\begin{array}{l}18.83 \\
(14)\end{array}$ & $\begin{array}{l}22.41 \\
(27)\end{array}$ & $\begin{array}{l}10.39 \\
(13)\end{array}$ & $\begin{array}{l}-11.26 \\
(11)\end{array}$ & $\begin{array}{l}-18.86 \\
(11)\end{array}$ & $\begin{array}{l}-7.91 \\
(6)\end{array}$ & $\begin{array}{l}14.79 \\
(11)\end{array}$ & $\begin{array}{l}8.56 \\
(4)\end{array}$ \\
\hline $\mathrm{LHV}\left(\mathrm{MJ} / \mathrm{m}^{3} \mathrm{STP}\right)$ & 1 & 18.99 & $\begin{array}{l}5.82 \\
(18) \\
\end{array}$ & $\begin{array}{l}5.88 \\
(25) \\
\end{array}$ & $\begin{array}{l}2.66 \\
(12) \\
\end{array}$ & $\begin{array}{l}-3.25 \\
(11)\end{array}$ & $\begin{array}{l}-5.21 \\
(14)\end{array}$ & $\begin{array}{l}-2.00 \\
(5)\end{array}$ & $\begin{array}{l}-3.73 \\
(10)\end{array}$ & $\begin{array}{l}2.38 \\
(4) \\
\end{array}$ \\
\hline
\end{tabular}

Response $=$ Ind. $+\mathrm{G}$ term $\cdot \mathrm{G}+\mathrm{C}$ term $\cdot \mathrm{C}+\mathrm{GC}$ term $\cdot \mathrm{G} \cdot \mathrm{C}+\mathrm{G}^{2}$ term $\cdot \mathrm{G}^{2}+\mathrm{C}^{2}$ term $\cdot \mathrm{C}^{2}+\mathrm{G}^{2} \mathrm{C}$ term $* \mathrm{C}+\mathrm{GC} \mathrm{C}^{2}$ term $\cdot \mathrm{G} \cdot \mathrm{C}^{2}+\mathrm{G}^{2} \mathrm{C}^{2}$ term $\cdot \mathrm{G}^{2} \cdot \mathrm{C}^{2}$

$\mathrm{G}=$ glycerol/glycerol+bio-oil $\mathrm{C}=$ catalyst/glycerol+bio-oil. Numbers in brackets indicate the percentage Pareto influence of each factor on the response variable. Pareto values represent the percentage of the orthogonal estimated total value. n.s. $=$ Non significant with $95 \%$ confidence.

The proportion of $\mathrm{CO}_{2}$ in the gas is strongly affected by the composition of the feed. An increase in the relative amount of crude glycerol in the mixture produces a decrease in the proportion of $\mathrm{CO}_{2}$ in the gas product. In addition, several interactions between the feedstock composition and the catalyst are responsible for the variations observed in the proportion of $\mathrm{CO}$. The relative amount of this gas is very small, which indicates that the water gas shift reaction is shifted towards $\mathrm{H}_{2}$ and $\mathrm{CO}_{2}$ production. This development also means that the variations observed for $\mathrm{CO}$ are not very important from a practical point of view. The effect of the feedstock and catalyst loading and the most important 
interactions between the variables detected with the ANOVA analysis on the composition and LHV of the gas phase are shown in Figure 3.

(a)

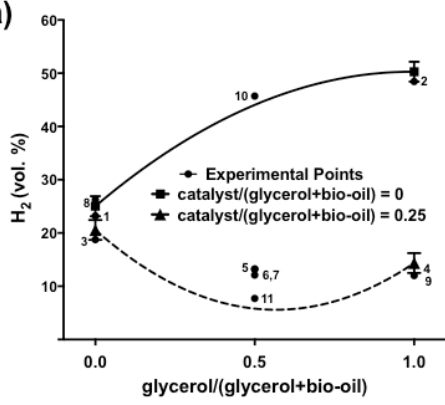

(b)

(d)
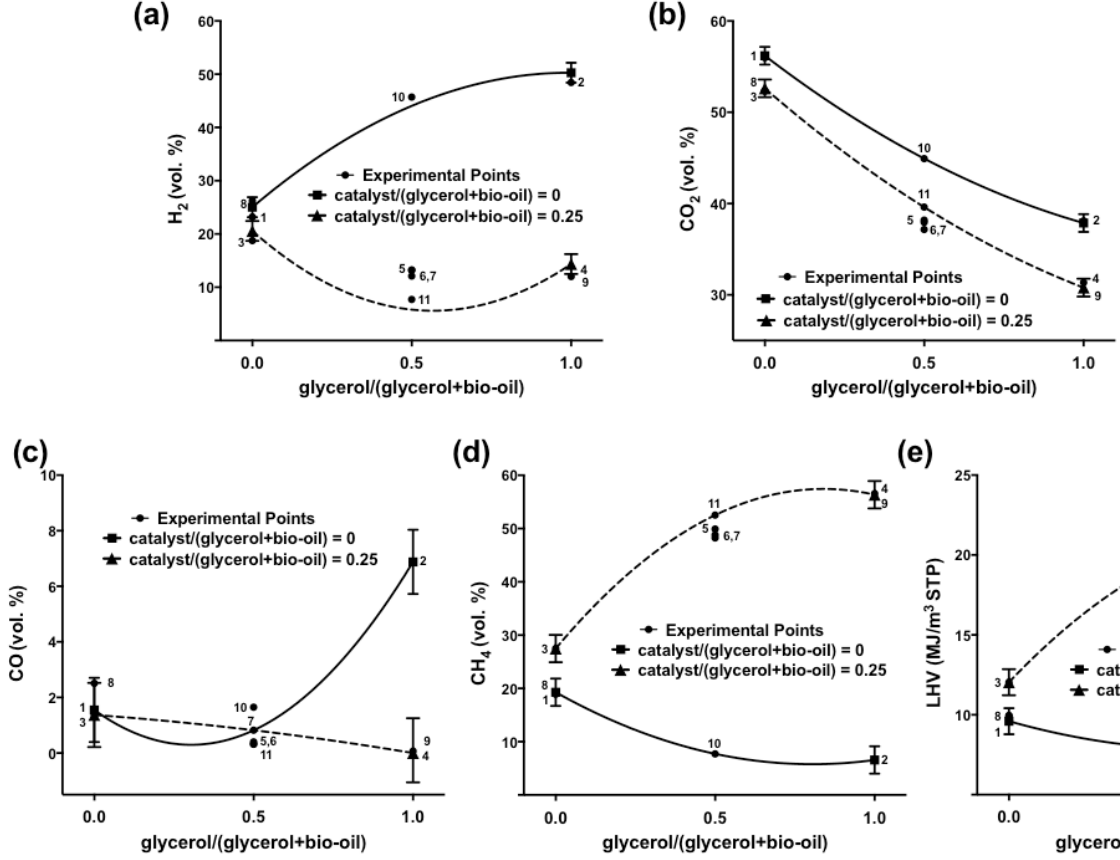

(e)

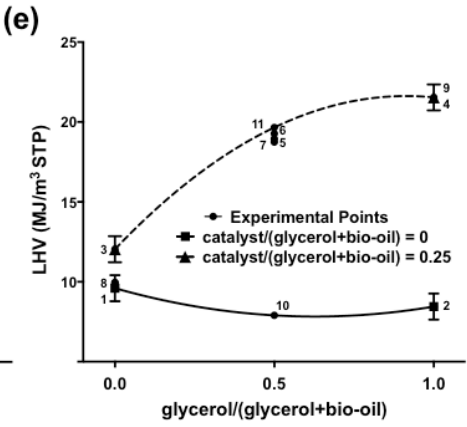

Figure 3. Influence of the feedstock composition and catalyst loading on the relative amounts of $\mathrm{H}_{2}$ (a), $\mathrm{CO}_{2}$ (b), $\mathrm{CO}$ (c) and $\mathrm{CH}_{4}$ (d) and the LHV (e) of the gas phase. Bars are LSD intervals with $95 \%$ confidence.

The effect of the feedstock composition on the composition of the gas phase depends on the amount of catalyst used in the valorisation process. On the one hand, for noncatalytic experiments ( $0 \mathrm{~g}$ catalyst/g organics), a progressive increase in the proportion of crude glycerol in the mixture leads to a sharp increase in the relative amount of $\mathrm{H}_{2}$ along with a small decrease in the proportion of $\mathrm{CH}_{4}$ in the gas. These variations are notably marked between 0 and $0.6 \mathrm{~g}$ crude glycerol/g organics. A further increase in the amount of crude glycerol up to $1 \mathrm{~g}$ crude glycerol/g organics does not significantly modify the proportion of $\mathrm{H}_{2}$ and $\mathrm{CH}_{4}$ in the gas. In addition, the proportion of $\mathrm{CO}_{2}$ decreases at higher glycerol concentrations in the feed, while a slight increase in the proportion of $\mathrm{CO}$ in the gas is also observed. These variations are thought to be the 
consequence of two factors: first, the higher proportion of $\mathrm{H}$ in crude glycerol than in bio-oil and second, the higher gas yield occurring with crude glycerol than with bio-oil.

It is also observed that an increase in the catalyst loading from 0 to $0.25 \mathrm{~g}$ catalyst/ $\mathrm{g}$ organics leads to a substantial increase in the relative amount of $\mathrm{CH}_{4}$ together with a decrease in the $\mathrm{H}_{2}$ content of the gas. These variations are more evident for higher proportions of crude glycerol in the feed. In particular, for the highest amount of catalyst ( $0.25 \mathrm{~g}$ catalyst/g organics), an increase in the crude glycerol content of the feed leads to an increase in the proportion of $\mathrm{CH}_{4}$ along with a and decrease in the relative amount of $\mathrm{H}_{2}$; thus leading to a substantial increase in the LHV of the gas. The variations observed in the proportions of $\mathrm{H}_{2}$ and $\mathrm{CH}_{4}$ in the gas are accounted for by the greater spread of the methanation reactions in the presence of the catalyst for crude glycerol than for bio-oil. Methane formation is favoured under these operating conditions. The presence of the catalyst also promotes the methanation reaction [36, 40], which explains both the decrease and the increase in the concentrations of $\mathrm{H}_{2}$ and $\mathrm{CH}_{4}$, respectively. Moreover, the thermodynamic proportion of $\mathrm{CH}_{4}$ in the gas is higher for crude glycerol than for bio-oil under the operating conditions used in this work.

\subsection{Liquid phase (upgraded bio-oil) properties}

\subsubsection{Elemental analysis and Higher Heating Value (HHV)}

The proportions of $\mathrm{C}, \mathrm{H}$ and $\mathrm{O}$ in the liquid product (upgraded bio-oils) (Table 3) vary by $66-77$ wt.\%, $7-11$ wt.\% and 15-25 wt.\%, while the HHV of the treated liquid shifts from 29 to $34 \mathrm{MJ} / \mathrm{kg}$. The comparison of these values with those of the original bio-oil (Table 1) reveals a substantial increase in the relative amounts of $\mathrm{C}$ and $\mathrm{H}$ and $\mathrm{HHV}$ together with a substantial decrease in the proportion of $O$. Therefore, this treatment 
effectively upgrades the original bio-oil into a liquid fuel with appropriate physicochemical properties, thus confirming that bio-oil upgrading in SCW is a promising route to produce liquid biofuels from lignocellulosic bio-oil [10]. The influence of the feed composition and catalyst loading on the elemental composition and HHV of the upgraded liquid is listed in Table 6.

The ANOVA analysis shows that the proportion of $\mathrm{H}$ in the upgraded liquid is strongly affected by the amount of crude glycerol in the feed. The composition of the feedstock also exerts a significant influence on the proportions of $\mathrm{C}$ and $\mathrm{O}$ and on the $\mathrm{HHV}$ of the upgraded liquid. Figure 4 plots the effect of the feedstock and catalyst loading together with the most important interactions between these two variables detected with the ANOVA analysis on the elemental composition and HHV of the liquid phase.

Table 6. Effects of the glycerol/organics and catalyst/organics ratios on the properties of the upgraded bio-oil.

\begin{tabular}{|c|c|c|c|c|c|c|c|c|c|c|}
\hline Response & $\mathbf{R}^{2}$ & Ind & $\mathbf{G}$ & $\mathbf{C}$ & GC & $\mathbf{G}^{2}$ & $\mathbf{C}^{2}$ & $\mathrm{G}^{2} \mathrm{C}$ & GC $^{2}$ & $\mathrm{G}^{2} \mathrm{C}^{2}$ \\
\hline $\mathrm{C}(\mathrm{wt} . \%)$ & 0.95 & 73.80 & n.s. & n.s. & $\begin{array}{l}-2.52 \\
(23)\end{array}$ & $\begin{array}{l}-4.59 \\
(35)\end{array}$ & n.s. & $\begin{array}{l}1.98 \\
(18)\end{array}$ & $\begin{array}{l}-2.71 \\
(25)\end{array}$ & n.s. \\
\hline H (wt.\%) & 1 & 7.31 & $\begin{array}{l}1.46 \\
(48)\end{array}$ & n.s. & $\begin{array}{l}0.38 \\
(10)\end{array}$ & $\begin{array}{l}1.35 \\
(29)\end{array}$ & n.s. & $\begin{array}{l}0.49 \\
(13)\end{array}$ & n.s. & n.s. \\
\hline O (wt.\%) & 0.93 & 71.68 & n.s. & n.s. & $\begin{array}{l}12.04 \\
(24)\end{array}$ & $\begin{array}{l}22.43 \\
(33)\end{array}$ & n.s. & $\begin{array}{l}37.21 \\
(43)\end{array}$ & n.s. & n.s. \\
\hline $\mathrm{HHV}(\mathrm{MJ} / \mathrm{kg})$ & 0.98 & 32.56 & $\begin{array}{l}1.55 \\
(24)\end{array}$ & $\begin{array}{l}-0.56 \\
(22)\end{array}$ & $\begin{array}{l}-0.58 \\
(12)\end{array}$ & n.s. & n.s. & $\begin{array}{l}2.17 \\
(25)\end{array}$ & $\begin{array}{l}-0.85 \\
(10)\end{array}$ & $\begin{array}{l}-0.46 \\
(7)\end{array}$ \\
\hline C. Acids (Area \%) & 0.90 & 16.37 & n.s. & $\begin{array}{l}-18.71 \\
(45)\end{array}$ & $\begin{array}{l}-13.88 \\
(27)\end{array}$ & n.s. & n.s. & n.s. & $\begin{array}{l}13.88 \\
(27)\end{array}$ & n.s. \\
\hline Furans (Area \%) & 0.95 & 1.44 & $\begin{array}{l}-2.73 \\
(61)\end{array}$ & $\begin{array}{l}1.17 \\
(2)\end{array}$ & n.s. & $\begin{array}{l}1.29 \\
(20)\end{array}$ & n.s. & $\begin{array}{l}-1.64 \\
(17)\end{array}$ & n.s. & n.s. \\
\hline Phenols (Area \%) & 1 & 52.76 & $\begin{array}{l}-20.88 \\
(27)\end{array}$ & $\begin{array}{l}37.65 \\
(12)\end{array}$ & $\begin{array}{l}5.11 \\
(5)\end{array}$ & $\begin{array}{l}-31.82 \\
(26)\end{array}$ & $\begin{array}{l}-5.08 \\
(2)\end{array}$ & $\begin{array}{l}-42.76 \\
(26)\end{array}$ & n.s. & $\begin{array}{l}4.99 \\
(2)\end{array}$ \\
\hline Ketones (Area \%) & 0.97 & 3.46 & $\begin{array}{l}-4.97 \\
(24)\end{array}$ & $\begin{array}{l}-4.57 \\
(22)\end{array}$ & $\begin{array}{l}5.49 \\
(22)\end{array}$ & n.s. & $\begin{array}{l}9.34 \\
(15)\end{array}$ & n.s. & n.s. & $\begin{array}{l}-7.31 \\
(17)\end{array}$ \\
\hline Cyclics (Area \%) & 0.99 & 22.59 & $\begin{array}{l}-9.48 \\
(21)\end{array}$ & $\begin{array}{l}-13.59 \\
\text { (3) }\end{array}$ & $\begin{array}{l}-17.13 \\
(32)\end{array}$ & $\begin{array}{l}-12.33 \\
(12)\end{array}$ & n.s. & $\begin{array}{l}22.68 \\
(24)\end{array}$ & n.s. & $\begin{array}{l}6.87 \\
(7)\end{array}$ \\
\hline
\end{tabular}

Response $=$ Ind. $+\mathrm{G}$ term $\cdot \mathrm{G}+\mathrm{C}$ term $\cdot \mathrm{C}+\mathrm{GC}$ term $\cdot \mathrm{G} \cdot \mathrm{C}+\mathrm{G}^{2}$ term $\cdot \mathrm{G}^{2}+\mathrm{C}^{2}$ term $\cdot \mathrm{C}^{2}+\mathrm{G}^{2} \mathrm{C}$ term $* \mathrm{C}+\mathrm{GC}^{2}$ term $\cdot \mathrm{G} \cdot \mathrm{C}^{2}+\mathrm{G}^{2} \mathrm{C}^{2}$ $\operatorname{term} \cdot \mathrm{G}^{2} \cdot \mathrm{C}^{2}$

$\mathrm{G}=$ glycerol/glycerol+bio-oil $\mathrm{C}=$ catalyst/glycerol+bio-oil. Numbers in brackets indicate the percentage Pareto influence of each factor on the response variable. Pareto values represent the percentage of the orthogonal estimated total value. n.s. $=$ Non significant with $95 \%$ confidence

The effect of the glycerol/organics ratio depends on the amount of catalyst used in the 
experiments. For non-catalytic experiments ( $0 \mathrm{~g}$ catalyst/g organics $)$, an increase in the proportion of crude glycerol between 0 and $0.5 \mathrm{~g}$ crude glycerol $/ \mathrm{g}$ organics in the feed results in an increase and a decrease in the proportions of $\mathrm{C}$ and $\mathrm{O}$, respectively, while the relative amount of $\mathrm{H}$ in the liquid remains unaltered. This leads to a substantial increase in the HHV of the upgraded liquid due to the sharp decrease occurring in the proportion of $\mathrm{O}$ in the liquid. These developments are accounted for by a greater spread of deoxygenation and thermal cracking reactions $[13,17,37,38]$, which are believed to be promoted by the presence of crude glycerol in the feed. The addition of crude glycerol helps decrease char formation, thus leading to an increase in the $\mathrm{C}$ content of the treated liquid. A further increase in the crude glycerol content of the feed up to $1 \mathrm{~g}$ crude glycerol/organics significantly rises the concentrations of $\mathrm{H}$ and $\mathrm{O}$ in the liquid and lowers the relative amount of $\mathrm{C}$. These variations lead to a small decrease in the HHV of the treated liquid. The addition of crude glycerol in the system can promote bio-oil hydrogenation as $\mathrm{H}_{2}$ is produced from crude glycerol decomposition. This may enhance bio-oil hydrogenation reactions, thus increasing the relative amount of $\mathrm{H}$ in the upgraded bio-oil.

The catalyst loading significantly influences the elemental analysis and calorific value of the upgraded bio-oil, but its effect depends on the composition of the feedstock. On the one hand, between 0 and $0.5 \mathrm{~g}$ crude glycerol/g organics, increasing the catalyst loading from 0 to $0.25 \mathrm{~g}$ catalyst/g organics leads to an increase and decrease in the relative amounts of $\mathrm{C}$ and $\mathrm{O}$, respectively, without modifying the relative proportion of $\mathrm{H}$ in the liquid. These variations produce a significant increase in the HHV of the liquid, especially between 0 and $0.4 \mathrm{~g}$ crude glycerol/g organics. The catalyst promotes deoxygenation and thermal cracking reactions $[13,17,37,38]$, which decreases the 
amount of $\mathrm{O}$ in the treated bio-oil. In addition, the lower char formation in these experiments helps to produce an upgraded bio-oil with a greater proportion of $\mathrm{C}$.
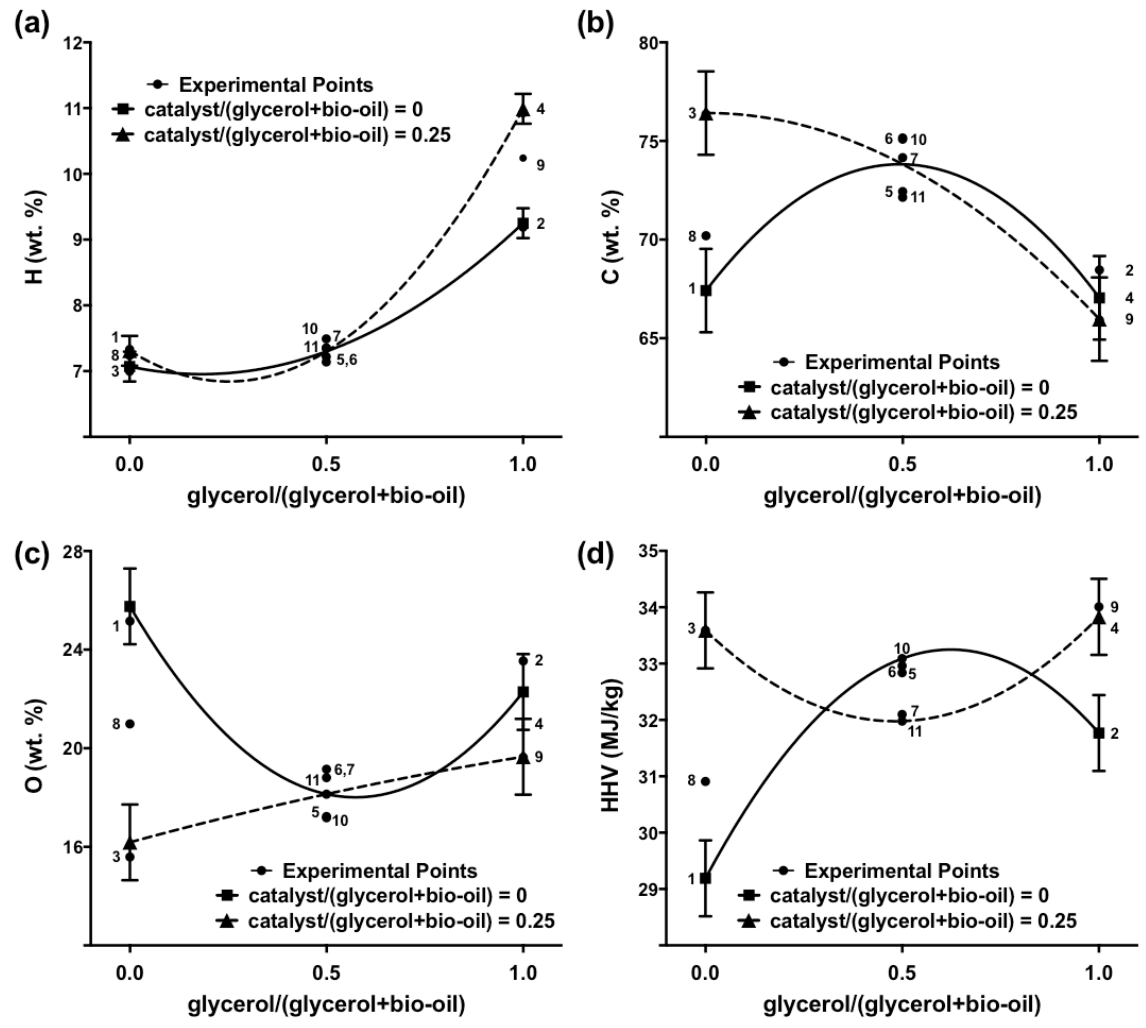

Figure 4. Influence of the feedstock composition and catalyst loading on the relative amounts of $\mathrm{H} \mathrm{(a),} \mathrm{C} \mathrm{(b)} \mathrm{and} \mathrm{O}$ (c) and the HHV (d) of the upgraded bio-oil. Bars are LSD intervals with $95 \%$ confidence.

On the other hand, from 0.5 and $1 \mathrm{~g}$ crude glycerol/organics, the same increase in the catalyst loading produces a significant increase in the proportion of $H$, while the proportions of $\mathrm{C}$ and $\mathrm{O}$ remain unaffected. The bio-oil HHV is not greatly affected due to the small variations occurring in its elemental composition. This increase in the proportion of $\mathrm{H}$ is believed to be the consequence of the increase in the amount of $\mathrm{H}_{2}$ produced from glycerol decomposition in the gas, as described earlier. Within this interval for the crude glycerol/organics ratio, a negligible solid production occurs due to 
the positive effect that crude glycerol has towards char reduction, which masks the positive effect of the catalyst. As a result, the proportion of $\mathrm{C}$ in the treated bio-oil is not affected by the catalyst loading between 0.5 and $1 \mathrm{~g}$ crude glycerol/organics.

\subsubsection{Chemical analysis}

The analysis of the composition of the upgraded liquid reveals that it is composed of a complex mixture of carboxylic acids (0-73\%), furans (0-7\%), phenols (0-85\%), ketones $(0-22 \%)$ and cyclic compounds (0-53\%). None of these compounds were detected in the liquid produced in experiments 4 and 9 as glycerol was converted into either gas or water-soluble liquids. These liquids were not recovered in the liquid-liquid extraction and remained in the aqueous phase. For these two experiments the liquid yield is very low $(<2 \%)$ and the GC-MS analysis did not identify any product. This suggests the formation of liquid compounds with high molecular weight that cannot be determined by GC-MS. Carboxylic acids include hexa, hepta and octadecaonic acids. Furans comprise furfural, 2-methyl-5-hydroxybenzofuran and 5-ethyl-2-furaldehyde. Phenols include methoxy phenolics such as phenol, phenol 2-methoxy, phenol 2,6-dimethoxy and phenol 2 methoxy-4methyl, along with alkyl phenols such as 2/3/4 methyl/ethyl/propyl phenols, phenol 2,6-dimethyl and phenol 2-ethyl-6-methyl. Ketones include methoxy-phenyl ketones and cyclic ketones. Cyclic compounds consist of hexacyclo-octadecanes, napthalenes, anthracenes, phenantrenes, and fluorenes. The concentrations of furans, phenols and cyclic compounds in the upgraded bio-oil are strongly influenced by the proportion of crude-glycerol in the feed, while the catalyst loading exerts a great influence on the relative amounts of carboxylic acids and ketones. 
Figure 5 plots the effects of the feedstock composition, catalyst loading and interactions between these two variables on the chemical composition of the liquid phase. The composition of the feed has a significant influence on the chemical composition of the liquid with different developments occurring depending on the catalyst loading. In the absence of the catalyst, a progressive increase in the proportion of glycerol in the feed produces a significant decrease in the relative amounts of furans, phenols and ketones along with a substantial increase in the proportion of carboxylic acids. The proportion of cyclic compounds initially increases between 0 and $0.5 \mathrm{~g}$ crude glycerol/g organics, reaching a maximum, and then decreases at higher proportions of crude-glycerol. The increase observed for the proportion of carboxylic acids shows a linear trend, while the variations in the concentrations of the other compounds are not linear, which might suggest a synergetic interaction between crude glycerol and bio-oil during this valorisation process. In particular, between 0 and $0.5 \mathrm{~g}$ crude glycerol $/ \mathrm{g}$ organics, an increase in the proportion of glycerol decreases the proportions of phenols and furans and increases the proportion of cyclic compounds, the relative amount of ketones being unaffected. A further increase in the relative amount of crude glycerol in the feed up to $1 \mathrm{~g}$ crude glycerol/g organics decreases the proportions of ketones and cyclic compounds without significantly modifying the concentrations of phenols and furans.

The progressive increase in the concentration of carboxylic acids with the addition of crude glycerol is believed to be the result of the progressive transformation of the fatty acid methyl esters initially present in crude glycerol into long chain carboxylic acids which can be solubilised in the upgraded bio-oil. For non-catalytic experiments, low gas formation takes place and the liquid yield decreases with the progressive addition of 
crude glycerol in the feed. Under such conditions, low molecular water soluble liquids, which are not preferentially solubilised in chloroform, are produced. Fatty acids are partially soluble in chloroform and can therefore be easily recovered though liquidliquid extraction. The low bio-oil yield and the solubility of these acids in chloroform leads to low yields of upgraded liquid with a high concentration of the acids.

(a)

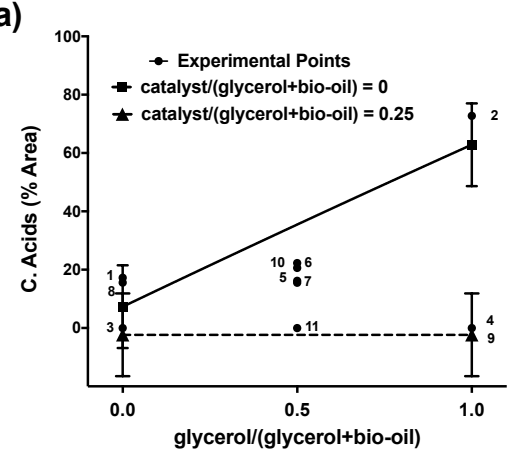

(c)

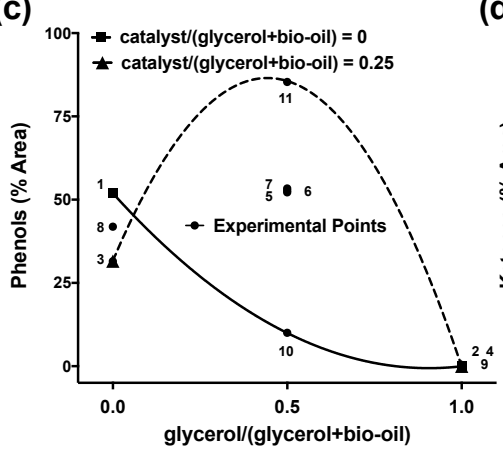

(b)

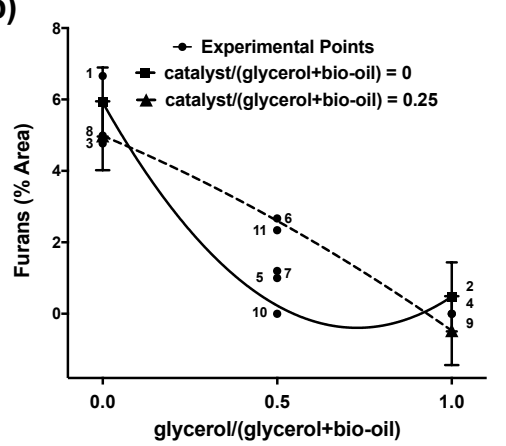

(e)

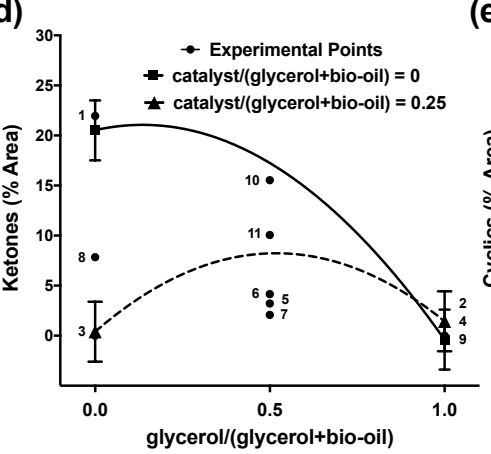

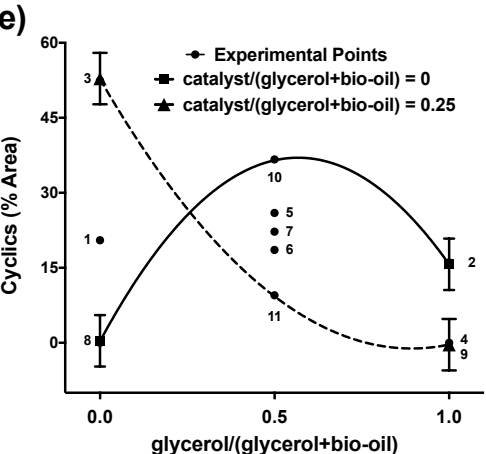

Figure 5. Influence of the feedstock composition and catalyst loading on the relative amounts of carboxylic acids (a), furans (b), phenols (c) ketones (d) and cyclic compounds (e) in the upgraded bio-oil. Bars are LSD intervals with 95\% confidence.

The upsurge and reduction in the proportions of cyclic compounds and phenols, respectively, is thought to be the consequence of the progressive hydrogenation of phenols to produce cyclic compounds by means of the $\mathrm{H}_{2}$ generated in situ [13] resulting from the progressive addition of crude glycerol into the mixture. This development was also observed in our previous works $[10,16]$ and has also been reported elsewhere [15]. The concentration of ketones remains steady between 0 and 0.5 
g crude glycerol/organics, while a further increase in the proportion of glycerol leads to a sharp decrease in the proportion of these compounds, probably due to the lower biooil yield and the sharp increase in the proportion of carboxylic acids. These developments also produce a decrease in the proportions of furans and cyclic compounds.

The presence of the catalyst determines the effect that crude glycerol exerts on the chemical composition of the liquid. In general, increasing the catalyst loading from 0 to $0.25 \mathrm{~g}$ catalyst/g organics results in a progressive increase in the proportions of furans and phenols together with a decrease in the proportions of carboxylic acids and ketones. The catalyst effectively promotes the WGS and reforming reactions towards gas formation $[10,16]$. In addition, Fisk et al. [13] found that the low molecular oxygenated species of the bio-oil are more likely to evolve towards the formation of gaseous products by reforming and water gas shift reactions in the presence of a catalyst than other organic species present in the bio-oil. This can produce a decrease in the proportion of carboxylic acids and ketones and consequently an increase in the proportions of furans and phenols, these latter compounds being less likely to be transformed into gas [13]. The effect of the catalyst on the relative amount of phenols and cyclic compounds significantly depends on the proportion of crude glycerol in the feed. While an increase in the proportion of cyclic compounds together with a decrease in the concentration of phenols occur when increasing the catalyst loading for rich biooil mixtures, the opposite takes place for mixtures concentrated in crude glycerol; i.e. the concentration of cyclic compounds and phenols decreases and increases, respectively. For rich bio-oil mixtures, an increase in the catalyst loading might promote the transformation of phenols into cyclic compounds as described above. The decrease 
observed for mixtures enriched with crude glycerol might account for the increase in gas formation [10].

In the presence of the catalyst, a progressive increase in the proportion of crude glycerol in the feed results in lower proportions of furans. In contrast, the proportions of carboxylic acids and ketones are barely affected by the presence of glycerol. Conversely, the concentration of glycerol in the feed exerts a great influence on the proportions of phenols and cyclic compounds. An increase in the crude glycerol content in the feed up to $0.5 \mathrm{~g}$ crude-glycerol $/ \mathrm{g}$ organics leads to a sharp increase in the proportion of phenols together with a pronounced decrease in the relative amount of cyclic compounds. This allows a maximum and a minimum in the concentration of these two compounds to be reached for the former and the latter, respectively. Crude glycerol might help decrease char formation, which leads to an increase in the liquid yield along with a decrease in the solid yield. Phenols are largely responsible for char production during the thermal treatment of bio-oil [41] and therefore the positive solid inhibitory effect of crude glycerol can help prevent the evolution of these compounds towards char. Crude glycerol exerts a positive effect on the thermal stabilisation of aromatics [5, 19], thus increasing their proportion in the treated liquid. Moreover, alkyl phenols can be produced during bio-oil upgrading due to the thermal cracking of high molecular weight lignin-derived compounds originally present in the bio-oil. A further increase in the proportion of crude glycerol up to $1 \mathrm{~g}$ crude-glycerol/g organics leads to a decrease in the proportion of phenols in the liquid, keeping the relative amount of cyclic compounds unaltered and negligible. This decrease is the consequence of the high gas formation and low liquid yield observed with highly enriched crude glycerol solutions. 


\subsection{Theoretical optimisation}

Optimal conditions for the simultaneous production of gas and liquid biofuels were sought. Specifically, two optimisations were carried out for the simultaneous production of gaseous and liquid bio-fuels from the co-valorisation of bio-oil and crude glycerol. They comprise the maximisation of the gas and upgraded bio-oil (liquid) yields along with the minimisation of the yield to solid, aiming at the production of a liquid fuel with high HHV. Two scenarios were considered for the properties of the gas phase. The first intends at the production of a $\mathrm{H}_{2}$ rich gas and therefore, it comprises the maximisation of the gas yield and the concentration of $\mathrm{H}_{2}$ in the gas. The second is directed towards energy production and maximises the gas yield and the LHV of the gas. For the optimisation, a relative importance (from 1 to 5 ) has been given to each one of the objectives in order to come up with a solution that satisfies all the criteria. A relative importance of 5 was given to the global yields, while a relative importance of 3 was assigned to the properties of the gas or liquid (vol. $\% \mathrm{H}_{2}$, LHV of the gas and HHV of the liquid).

Taking these restrictions into account (Table 7), both optimisations predict an optimum condition when a feed consisting of approximately equal amounts of each material is employed. The catalyst loading significantly influences the composition of the gas phase, and therefore the process can be easily tailored by simply adding a catalyst. Experiments 10 and 11 were conducted using operating conditions very close to the values predicted in the optimisations and similar results were obtained; thus providing a good validation of the theoretical prediction obtained with the statistical analysis of the results. In particular, optimisation 1 predicts an optimum for $\mathrm{H}_{2}$ production in the absence of a catalyst. The yields to gas and upgraded liquid are $28 \%$ and $22 \%$, 
respectively. Under these conditions, the proportion of $\mathrm{H}_{2}$ in the gas and the HHV of the liquid are 46 vol.\% and $33 \mathrm{MJ} / \mathrm{kg}$. These conditions allow a $\mathrm{H}_{2}$ rich gas together with an upgraded liquid with a high HHV to be produced with a negligible solid formation. Considering the initial amount of bio-oil fed in the reactor, these conditions produce a treated bio-oil/original bio-oil yield of $44 \%$. However, around $49 \%$ of the organics of the feed (the vast majority of them being water soluble glycerol-derived compounds) cannot be recovered in the gas or the liquid (upgraded bio-oil) phase.

Table 7. Optimisation: restrictions, conditions and optimum values.

\begin{tabular}{|c|c|c|c|c|}
\hline \multirow[t]{2}{*}{ Optimisation } & \multicolumn{2}{|c|}{1} & \multicolumn{2}{|c|}{2} \\
\hline & Objective & Solution & Objective & Solution \\
\hline Crude-glycerol/organics (g) & & 0.53 & & 0.51 \\
\hline Catalyst/organics $(\mathrm{g} / \mathrm{g})$ & & 0 & & 0.25 \\
\hline \multicolumn{5}{|l|}{ Global results } \\
\hline Gas yield (\%) & Maximise (5) & $28 \pm 5.5$ & Maximise (5) & $84 \pm 5.5$ \\
\hline Liquid yield (\%) & Maximise (5) & $22 \pm 0.6$ & Maximise (5) & $18 \pm 0.6$ \\
\hline Solid yield (\%) & Minimise (5) & $0.8 \pm 0.14$ & Minimise (5) & $1 \pm 0.14$ \\
\hline \multicolumn{5}{|l|}{ Gas phase } \\
\hline $\mathrm{H}_{2}(\mathrm{vol} . \%)$ & Maximise (3) & $46 \pm 0.6$ & & $6.5 \pm 0.6$ \\
\hline $\mathrm{CO}_{2}(\mathrm{vol} . \%)$ & & $44 \pm 0.5$ & & $38.2 \pm 0.5$ \\
\hline CO (vol.\%) & & $1 \pm 0.6$ & & $0.78 \pm 0.6$ \\
\hline $\mathrm{CH}_{4}(\mathrm{vol} . \%)$ & & $9 \pm 0.8$ & & $55.2 \pm 0.8$ \\
\hline $\mathrm{LHV}\left(\mathrm{MJ} / \mathrm{m}^{3} \mathrm{STP}\right)$ & & $8.2 \pm 0.9$ & Maximise (3) & $20.5 \pm 0.9$ \\
\hline $\mathrm{HHV}\left(\mathrm{MJ} / \mathrm{m}^{3} \mathrm{STP}\right)$ & & $9.6 \pm 0.9$ & & $22.9 \pm 0.9$ \\
\hline $\mathrm{HHV}(\mathrm{MJ} / \mathrm{kg})$ & & $9.8 \pm 0.7$ & & $19.8 \pm 0.7$ \\
\hline \multicolumn{5}{|l|}{ Upgraded liquid } \\
\hline $\mathrm{C}(\mathrm{wt} . \%)$ & & $73.7 \pm 1.3$ & & $73.5 \pm 1.3$ \\
\hline H (wt.\%) & & $7.5 \pm 0.1$ & & $7.4 \pm 0.1$ \\
\hline $\mathrm{O}(\mathrm{wt} . \%)$ & & $18.0 \pm 1.1$ & & $18.2 \pm 1.1$ \\
\hline HHV (MJ/kg) & Maximise (3) & $33.2 \pm 0.8$ & Maximise (3) & $32.1 \pm 0.3$ \\
\hline Phenols (Area \%) & & $8.1 \pm 0.5$ & & $80.5 \pm 0.5$ \\
\hline Carboxylic Acids (Area \%) & & $38.0 \pm 1.5$ & & $0 \pm 1.5$ \\
\hline Cyclic compounds (Area \%) & & $36.3 \pm 2.7$ & & $9.36 \pm 2.7$ \\
\hline Furans (Area \%) & & $0.1 \pm 0.5$ & & $2.3 \pm 0.5$ \\
\hline Ketones (Area \%) & & $15.4 \pm 1.8$ & & $6.5 \pm 1.8$ \\
\hline
\end{tabular}

Optimisation 2 predicts an optimum for the energy production from bio-oil and crude glycerol (49/51 wt.\%) when the highest amount of catalyst ( $0.25 \mathrm{~g}$ catalyst/g organics) is used. These conditions not only result in a negligible solid formation $(<1 \%)$ but also allow the complete transformation of the feed into a gas (84\%) with a LHV and a HHV 
of $21 \mathrm{MJ} / \mathrm{m}^{3} \mathrm{STP}$ and $23 \mathrm{MJ} / \mathrm{m}^{3} \mathrm{STP}$ respectively, together with an upgraded bio-oil $(18 \%)$ with a HHV of $32 \mathrm{MJ} / \mathrm{kg}$. Considering the proportion of bio-oil and crude glycerol in the original mixture, under these conditions it is possible to transform up to $37 \%$ of the original bio-oil into a liquid product having a high proportion of phenolic compounds and a negligible concentration of carboxylic acids (thus increasing the stability of the oil), together with a HHV $(32 \mathrm{MJ} / \mathrm{kg}$ ) two times higher than the original material $(16 \mathrm{MJ} / \mathrm{kg})$. The rest of the bio-oil $(63 \%)$ and all the crude glycerol are transformed into a rich methane biogas $(55$ vol.\%) with a high calorific value (LHV = $21 \mathrm{MJ} / \mathrm{m}^{3} \mathrm{STP}$ and $\mathrm{HHV}=23 \mathrm{MJ} / \mathrm{m}^{3} \mathrm{STP}$ ). In addition, considering the gas and liquid yields along with the HHV of the gas in mass basis $(20 \mathrm{MJ} / \mathrm{kg})$ and the HHV of the feedstock (49/51 wt.\% bio-oil/crude glycerol, HHV=19 MJ/kg), these results represent a theoretical global energy efficiency of $100 \%$ due to the negligible solid formation. The elemental composition (74 wt.\% C, 7.5 wt.\% $\mathrm{H}$ and 18 wt.\% O) and HHV (32-33 $\mathrm{MJ} / \mathrm{kg}$ ) of the upgraded liquid are very similar in both optimisations. These results highlight the positive effect of crude glycerol during bio-oil upgrading in SCW. They represent an increase of $35 \%, 122 \%$ and $78 \%$ in the concentrations of $\mathrm{C}$ and $\mathrm{H}$ and HHV of the liquid, respectively, together with a decrease of $39 \%$ in the proportion of O with respect to the original bio-oil. Crude glycerol not only helps inhibit solid formation without compromising the yield to upgraded bio-oil, but also allows a rich $\mathrm{H}_{2} / \mathrm{CH}_{4}$ gas to be produced.

These promising results open the door for the scale-up and commercialisation of the process. This co-synergetic valorisation inhibits solids formation, which is one of the major drawbacks for the scale-up of this technology, and therefore it represents a step change for bio-oil upgrading. The formation of solids not only does deactivate the 
catalyst but also it leads to operational problems specially if continuous flow reactors are to used. A possible real application for this process might be the simultaneous production of diesel and gasoline substitutes in a single unit from renewable and low value bio-based feedstocks. This simultaneity helps the development of a circular bioeconomy and produces alternative bio-fuels for two of the most common internal combustion engines used at present. For example, from the co-valorisation of $500 \mathrm{~kg}$ of each material, it might be possible to produce $160 \mathrm{~kg}$ of upgraded bio-oil and $840 \mathrm{~kg}$ of bio-gas. The upgraded bio-oil has very similar fuel properties than diesel ( $85 \mathrm{wt} . \% \mathrm{C}$, 15 wt.\% H, $44.8 \mathrm{MJ} / \mathrm{kg}$ ) or biodiesel (75 wt.\% C, 12 wt.\% H, 11 wt.\% O, $40 \mathrm{MJ} / \mathrm{kg}$ ) [42] and therefore, it could be used in an diesel engine, either alone or blended with diesel and/or biodiesel [43]. This could help to decrease the net $\mathrm{CO}_{2}$ emissions without modifying the current vehicle fleet infrastructure.

In addition, the bio-gas produced in the process has a relatively high $\mathrm{CH}_{4}$ content (55 vol.\%); thus representing a very interesting and potential candidate to be used as a fuel in the current gasoline engines with minor modifications. In this regard, it might be also possible to improve the quality of the biogas by enriching its methane content to a level similar to that of natural gas [44]. With methane enrichment and the subsequent compression of the gas, it could be used as fuel to power motor vehicles that run on compressed natural gas (CNG) [45]. Besides, it could also be possible to use this biogas without enrichment. However, since biogas has a lower energy density than natural gas, the fuel injection systems might need some minor modifications [44]. Biogas lower emission levels compared to diesel makes it more desirable and climate friendly. Very interestingly, many vehicles can be converted to operate on both, conventional liquid fuels and biogas. This includes conversions from gasoline to gas/gasoline and from 
diesel to gas/diesel. It is also possible to run a diesel vehicle using a biogas/diesel blend (90 wt.\% biogas, $10 \mathrm{wt} . \%$ diesel) using a modified diesel engine [46]; this ratio being quite similar to that obtained in this work ( $84 \mathrm{wt} . \%$ biogas, $16 \mathrm{wt} . \%$ bio-oil). As an example, a diesel/biogas dual-fuel model has been demonstrated at farm-based biogas systems with systems running on a $95 / 5$ wt.\% biogas/diesel blend. In such cases, the biogas still contained 40 vol. $\% \mathrm{CO}_{2}$ and had not been upgraded to natural gas quality [47].

Therefore, the experimental results of this work might represent a step-change in future energy production, allowing the simultaneous production of liquid and gaseous biofuels from biomass with many potential and promising applications. This could greatly help to reduce the current oil fuel dependency, allowing a progressive transition of the energy industry towards a greener and more sustainable energy market.

\section{Conclusions}

This work addresses the co-valorisation of lignocellulosic bio-oil and crude glycerol in supercritical water for the simultaneous production of gas and liquid bio-fuels. The most important conclusions are summarised below.

1. The gas, liquid (upgraded bio-oil) and solid yields varied by $4-87 \%, 0-46 \%$ and 0 $18 \%$, respectively. The gas yield is greatly influenced by the catalyst loading, the liquid yield by the composition of the feed, and the yield to solid by both the feed composition and the catalyst loading. A synergistic interaction between crude glycerol and bio-oil took place during the upgrading process which resulted in an important decrease in the solid yield, thus allowing the complete transformation of both materials into gas and liquid bio-fuels with negligible char formation. 
2. The gas phase was made up of $\mathrm{H}_{2}$ (7-49 vol.\%), $\mathrm{CO}_{2}$ (31-56 vol.), $\mathrm{CO}$ (0-7 vol.\%) and $\mathrm{CH}_{4}$ (6-57 vol.\%) and had a Lower Heating Value (LHV) ranging from 8 to 22 $\mathrm{MJ} / \mathrm{m}^{3} \mathrm{STP}$. The catalyst loading significantly influenced the relative amounts of $\mathrm{H}_{2}$ and $\mathrm{CH}_{4}$ and the LHV of the gas phase. A higher catalyst loading decreased the amount of $\mathrm{H}_{2}$ and increased the relative proportion of $\mathrm{CH}_{4}$ in the gas due to the greater spread of methanation reactions. This allowed the properties of the gas phase to be easily tailored; i.e. bio-oil and crude glycerol can be co-valorised towards either a rich $\mathrm{H}_{2}$ or $\mathrm{CH}_{4}$ gas with small changes in the amount of catalyst initially loaded.

3. The proportions of $\mathrm{C}, \mathrm{H}$ and $\mathrm{O}$ in the upgraded bio-oils shifted between $66-77$ wt.\%, 7-11 wt.\% and 15-25 wt.\%, respectively, while the HHV of the treated liquid ranged from 29 to $34 \mathrm{MJ} / \mathrm{kg}$. This represents an increase of up to $43 \%, 231 \%$ and $84 \%$ in the proportions of $\mathrm{C}$ and $\mathrm{H}$, and in the $\mathrm{HHV}$, respectively, as well as a decrease of up to $40 \%$ in the proportion of $\mathrm{O}$ in comparison with the raw material. The feed composition and catalyst loading influenced the elemental analysis of the treated liquid. The addition of crude glycerol helped to decrease char formation and increase the $\mathrm{C}$ content of the treated liquid when rich bio-oil solutions were used ( $>50 \mathrm{wt} . \%)$.

4. The upgraded bio-oil consisted of a mixture of carboxylic acids $(0-73 \%)$, furans $(0-$ $7 \%$, phenols $(0-85 \%)$, ketones $(0-22 \%)$ and cyclic compounds $(0-53 \%)$. For noncatalytic experiments, an increase in the proportion of crude glycerol augmented the proportion of carboxylic acids and cyclic compounds and decreased the proportion of phenols. This is accounted for by the dissolution in the bio-oil of the fatty acids originally present in the crude glycerol and the hydrogenation of phenolic compounds present in the bio-oil yielding cyclic compounds with the $\mathrm{H}_{2}$ produced in the process. In the presence of a catalyst, the addition of low amounts of crude glycerol increased the relative amounts of phenols and decreased the relative amounts of cyclic compounds. 
This occurred due to two facts: the positive thermal stabilising effect of crude glycerol, which prevents the evolution of bio-oil-derived aromatic compounds to char, and the lower reactivity towards gas formation of the phenols compared to that of the other organics present in bio-oil .

5. Optimum conditions for the simultaneous production of gas and liquid biofuels from the co-valorisation of bio-oil and crude glycerol in SCW were found with a feed having equal amounts of each material using a $0.25 \mathrm{~g}$ catalyst/g organics ratio. Under these conditions, $37 \%$ of the original bio-oil was transformed into an upgraded liquid with a HHV (32 MJ/kg) two times higher than that of the original bio-oil. The remaining biooil and all the crude glycerol fed were converted into a rich $\mathrm{CH}_{4}$ biogas (55 vol.\%) with a high LHV (21 MJ/m³ STP).

\section{Acknowledgements}

The authors wish to express their gratitude to the Aragon Government (GPT group), European Social Fund and the Spanish MINECO (projects ENE2010-18985 and ENE2013-41523-R) for providing financial support. In addition, Javier Remón Núñez would like to express his gratitude to the Spanish MINECO for the FPI (BES- 2011044856) and mobility (EEBB-I-14-08688 and EEBB-I-15-09588) grants awarded. In addition, the lab and analytical facilities as well as the kind support of Dr. M. Millan are gratefully acknowledged.

\section{References}

[1] Ayhan D. Biofuels sources, biofuel policy, biofuel economy and global biofuel projections. Energy Conversion and Management. 2008;49:2106-16.

[2] Ma W, Liu B, Zhang R, Gu T, Ji X, Zhong L, et al. Co-upgrading of raw bio-oil with kitchen waste oil through fluid catalytic cracking (FCC). Applied Energy. 2018;217:233-40. 
[3] Varrone C, Liberatore R, Crescenzi T, Izzo G, Wang A. The valorization of glycerol: Economic assessment of an innovative process for the bioconversion of crude glycerol into ethanol and hydrogen. Applied Energy. 2013;105:349-57.

[4] Ayalur Chattanathan S, Adhikari S, Abdoulmoumine N. A review on current status of hydrogen production from bio-oil. Renewable and Sustainable Energy Reviews. 2012;16:2366-72.

[5] Jacobson K, Maheria KC, Kumar Dalai A. Bio-oil valorization: A review. Renewable and Sustainable Energy Reviews. 2013;23:91-106.

[6] Xiu S, Shahbazi A. Bio-oil production and upgrading research: A review. Renewable and Sustainable Energy Reviews. 2012;16:4406-14.

[7] Sipillä K, Kuoppala E, Fagernas L, Oasmaa A. Characterization of biomass-based flash pyrolysis oils. Biomass Bioenerg. 1998;14:103-13.

[8] Trane R, Dahl S, Skjøth-Rasmussen MS, Jensen AD. Catalytic steam reforming of bio-oil. International Journal of Hydrogen Energy. 2012;37:6447-72.

[9] Lu Q, Li W-Z, Zhu X-F. Overview of fuel properties of biomass fast pyrolysis oils. Energy Conversion and Management. 2009;50:1376-83.

[10] Remón J, Arcelus-Arrillaga P, García L, Arauzo J. Production of gaseous and liquid bio-fuels from the upgrading of lignocellulosic bio-oil in sub- and supercritical water: Effect of operating conditions on the process. Energy Conversion and Management. 2016;119:14-36.

[11] Prajitno H, Insyani R, Park J, Ryu C, Kim J. Non-catalytic upgrading of fast pyrolysis bio-oil in supercritical ethanol and combustion behavior of the upgraded oil. Applied Energy. 2016;172:12-22.

[12] Zhang Q, Xu Y, Li Y, Wang T, Zhang Q, Ma L, et al. Investigation on the esterification by using supercritical ethanol for bio-oil upgrading. Applied Energy. 2015;160:633-40.

[13] Fisk CA, Morgan T, Ji Y, Crocker M, Crofcheck C, Lewis SA. Bio-oil upgrading over platinum catalysts using in situ generated hydrogen. Applied Catalysis A: General. 2009;358:150-6.

[14] Penninger J, Rep M. Reforming of aqueous wood pyrolysis condensate in supercritical water. Int J Hydrog Energy. 2006;31:1597-606.

[15] Onwudili JA, Williams PT. Catalytic conversion of bio-oil in supercritical water: Influence of $\mathrm{RuO} 2 / \gamma-\mathrm{A} 12 \mathrm{O} 3$ catalysts on gasification efficiencies and bio-methane production. Applied Catalysis B: Environmental. 2016;180:559-68.

[16] Remón J, Arauzo J, García L, Arcelus-Arrillaga P, Millan M, Suelves I, et al. Biooil upgrading in supercritical water using Ni-Co catalysts supported on carbon nanofibres. Fuel Processing Technology. 2016;154:178-87.

[17] Duan P, Bai X, Xu Y, Zhang A, Wang F, Zhang L, et al. Catalytic upgrading of crude algal oil using platinum/gamma alumina in supercritical water. Fuel. 2013;109:225-33.

[18] Zhang Y, Wang Y, Cui H, Zhao P, Song F, Sun X, et al. Effects of hydrolysis and oxidative hydrolysis pretreatments on upgrading of the water-soluble fraction of bio-oil via decarboxylation. Applied Energy. 2018;226:730-42.

[19] Sheu Y-HE, Anthony RG, Soltes EJ. Kinetic studies of upgrading pine pyrolytic oil by hydrotreatment. Fuel Processing Technology. 1988;19:31-50.

[20] Manosak R, Limpattayanate S, Hunsom M. Sequential-refining of crude glycerol derived from waste used-oil methyl ester plant via a combined process of chemical and adsorption. Fuel Processing Technology. 2011;92:92-9. 
[21] Markočič E, Kramberger B, van Bennekom JG, Jan Heeres H, Vos J, Knez Ž. Glycerol reforming in supercritical water; a short review. Renewable and Sustainable Energy Reviews. 2013;23:40-8.

[22] Onwudili JA, Williams PT. Hydrothermal reforming of bio-diesel plant waste: Products distribution and characterization. Fuel. 2010;89:501-9.

[23] van Bennekom JG, Venderbosch RH, Assink D, Heeres HJ. Reforming of methanol and glycerol in supercritical water. The Journal of Supercritical Fluids. 2011;58:99-113.

[24] Yu-Wu QM, Weiss-Hortala E, Barna R, Boucard H, Bulza S. Glycerol and bioglycerol conversion in supercritical water for hydrogen production. Environmental Technology. 2012;33:2245-55.

[25] Dou B, Rickett GL, Dupont V, Williams PT, Chen H, Ding Y, et al. Steam reforming of crude glycerol with in situ $\mathrm{CO} 2$ sorption. Bioresource technology. 2010;101:2436-42.

[26] Fermoso J, He L, Chen D. Production of high purity hydrogen by sorption enhanced steam reforming of crude glycerol. Int J Hydrog Energy. 2012;37:14047-54.

[27] Valliyappan T, Ferdous D, Bakhshi NN, Dalai AK. Production of Hydrogen and Syngas via Steam Gasification of Glycerol in a Fixed-Bed Reactor. Topics in Catalysis. 2008;49:59-67.

[28] Medrano JA, Oliva M, Ruiz J, Garcia L, Arauzo J. Catalytic steam reforming of acetic acid in a fluidized bed reactor with oxygen addition. Int $\mathrm{J}$ Hydrog Energy. 2008;33:4387-96.

[29] Medrano JA, Oliva M, Ruiz J, Garcia L, Arauzo J. Hydrogen from aqueous fraction of biomass pyrolysis liquids by catalytic steam reforming in fluidized bed. Energy. 2011;36:2215-24.

[30] Remón J, Broust F, Valette J, Chhiti Y, Alava I, Fernandez-Akarregi AR, et al. Production of a hydrogen-rich gas from fast pyrolysis bio-oils: Comparison between homogeneous and catalytic steam reforming routes. Int J Hydrog Energy. 2014;39:17182.

[31] Remón J, Medrano JA, Bimbela F, García L, Arauzo J. Ni/Al-Mg-O solids modified with $\mathrm{Co}$ or $\mathrm{Cu}$ for the catalytic steam reforming of bio-oil. Applied Catalysis B: Environmental. 2013;132-133:433-44.

[32] Remón J, Jarauta-Córdoba C, García L, Arauzo J. Analysis and optimisation of H2 production from crude glycerol by steam reforming using a novel two step process. Fuel Processing Technology. 2016;145:130-47.

[33] Pinilla JL, Arcelus-Arrillaga P, Puron H, Millan M. Selective Catalytic Steam Cracking of anthracene using mesoporous $\mathrm{Al} 2 \mathrm{O} 3$ supported Ni-based catalysts doped with Na, Ca or K. Applied Catalysis A: General. 2013;459:17-25.

[34] Channiwala SA, Parikh PP. A unified correlation for estimating HHV of solid, liquid and gaseous fuels. Fuel. 2002;81:1051-63.

[35] Chakinala AG, Chinthaginjala JK, Seshan K, van Swaaij WPM, Kersten SRA, Brilman DWF. Catalyst screening for the hydrothermal gasification of aqueous phase of bio-oil. Catalysis Today. 2012;195:83-92.

[36] Cherad R, Onwudili JA, Williams PT, Ross AB. A parametric study on supercritical water gasification of Laminaria hyperborea: a carbohydrate-rich macroalga. Bioresource technology. 2014;169:573-80.

[37] Duan P, Savage PE. Catalytic hydrotreatment of crude algal bio-oil in supercritical water. Applied Catalysis B: Environmental. 2011;104:136-43.

[38] Duan P, Savage PE. Catalytic treatment of crude algal bio-oil in supercritical water: optimization studies. Energy \& Environmental Science. 2011;4:1447. 
[39] Duan P, Savage PE. Upgrading of crude algal bio-oil in supercritical water. Bioresource technology. 2011;102:1899-906.

[40] Lu Y, Guo L, Ji C, Zhang X, Hao X, Yan Q. Hydrogen production by biomass gasification in supercritical water: A parametric study. Int J Hydrog Energy. 2006;31:822-31.

[41] Remón J, Broust F, Volle G, García L, Arauzo J. Hydrogen production from pine and poplar bio-oils by catalytic steam reforming. Influence of the bio-oil composition on the process. Int J Hydrog Energy. 2015;40:5593-608.

[42] Prakash R, Singh RK, Murugan S. Experimental investigation on a diesel engine fueled with bio-oil derived from waste wood-biodiesel emulsions. Energy. 2013;55:610-8.

[43] Cataluña R, Kuamoto PM, Petzhold CL, Caramão EB, Machado ME, da Silva R. Using Bio-oil Produced by Biomass Pyrolysis as Diesel Fuel. Energy \& Fuels. 2013;27:6831-8.

[44] Kadam R, Panwar NL. Recent advancement in biogas enrichment and its applications. Renewable and Sustainable Energy Reviews. 2017;73:892-903.

[45] Angelidaki I, Treu L, Tsapekos P, Luo G, Campanaro S, Wenzel H, et al. Biogas upgrading and utilization: Current status and perspectives. Biotechnology advances. 2018;36:452-66.

[46] Åhman M. Biomethane in the transport sector-An appraisal of the forgotten option. Energy Policy. 2010;38:208-17.

[47] Kirk JL, Bristow AL, Zanni AM. Exploring the market for Compressed Natural Gas light commercial vehicles in the United Kingdom. Transportation Research Part D: Transport and Environment. 2014;29:22-31. 